\title{
Multidisciplinary Integrated Care in Atrial Fibrillation (Micaf): ASystematic Review and Meta-Analysis
}

\author{
Adnan Khana ${ }^{1 *}$, Alberto Ceredab ${ }^{2}$, Claudia Waltherc ${ }^{3}$ and Aqsa Aslamd ${ }^{4}$ \\ ${ }^{1}$ Sharif Medical City Road, Jati Umra, Pakistan \\ ${ }^{2} H P G$ XXII Hospital, Bergamo, Italy \\ ${ }^{3}$ University Hospital of Theodor-Stern-Kai 7, Frankfurt Germany \\ ${ }^{4}$ Assistant Professor of Pathology, Sharif Medical and Dental College, Lahore
}

*Corresponding author: Adnan Khana, Assistant Professor of Pathology, Sharif Medical City, Lahore \& London School of Economics and Political Science, Sharif Medical City Road, Jati Umra, Lahore, Pakistan

To Cite This Article: Adnan Khana, Alberto Ceredab, Claudia Waltherc, Aqsa Aslamd. Multidisciplinary Integrated Care in Atrial Fibrillation (Micaf): ASystematic Review and Meta-Analysis. Am J Biomed Sci \& Res. 2021 - 13(4). AJBSR.MS.ID.001887. D0I: 10.34297/ AJBSR.2021.13.001887

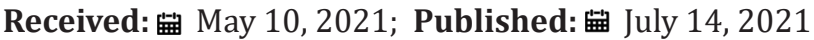

\begin{abstract}
Objective: To access the effectiveness of multidisciplinary integrated care in the clinical outcomes of atrial fibrillation patients

Methods: Medline, EMBASE and the CENTRAL trials registry of the Cochrane Collaboration were searched for articles on multidisciplinary integrated care in atrial fibrillation patients. The systematic review and meta-analysis included 6 and 5 articles, respectively that compared the outcomes between the integrated care group and control group.

Results: Multidisciplinary integrated care was concomitant with a decrease in all-cause mortality (OR 0.65, 95\%CI 0.44 to 0.95, p=0.028), MACE (OR 1.39, 95\%CI 1.19 to 1.62, p=0.000), AF-related hospitalization (OR 1.36, 95\%CI 0.99 to 1.87, $\mathrm{p}=0.056$ ), cardiovascular hospitalization (OR 0.66 , $95 \%$ CI 0.49 to $0.89, \mathrm{p}=0.007$ ) and cardiovascular mortality (OR $0.49,95 \% \mathrm{CI} 0.21$ to $1.17, \mathrm{p}=0.109$ ). The result was not statistically significant for cardiovascular mortality as only 2 studies reported this outcome. Multidisciplinary integrated care had no significant impact on the major bleeding (OR $1.02,95 \%$ CI 0.59 to $1.75, \mathrm{p}=0.945$ ) or minor bleeding (OR $0.90,95 \% \mathrm{CI} 0.66$ to $1.24, \mathrm{p}=0.52$ ) and cerebrovascular events (OR $1.38,95 \% \mathrm{CI} 0.84$ to 2.27 , $\mathrm{p}=0.20$ ).
\end{abstract}

Conclusion: In comparison to the usual care, a multidisciplinary integrated care approach in atrial fibrillation patients is associated with reduced MACE/NACE, cardiovascular and AF-related hospitalizations \& mortality and all-cause mortality.

Study registration: PROSPERO registration number CRD42018110613

Keywords: Multidisciplinary integrated care; Atrial fibrillation; Clinical outcomes

\section{Introduction}

Atrial fibrillation (AF) is the commonest cardiac arrhythmia diagnosed in nearly 30 million patients globally [1]. In the United States, an approximately 2.3 million people suffer from atrial fibrillation [2]. It is a global public health problem and is expected to rise in the coming years [3]. It poses a significant economic burden on healthcare systems accounting for a large number of hospital admissions. According to an estimate, hospitalizations due to $\mathrm{AF}$ increased by $23 \%$ from the year 2000 to 2010 [4]. The patients are at higher risk of developing congestive heart failure (CHF), stroke and systemic thromboembolism [5].

Wagner and colleagues introduced a chronic care model establishing that the chronic disease management requires a different approach in contrast to the standard medical care [6]. Multidisciplinary care represents the comprehensive case management strategy with a greater number of medical and social support personnel. Multidisciplinary care involves a 
multidisciplinary team that includes the primary care provider, other physicians, nurses, dietitians, pharmacists and social workers that provide long-term care to patients with chronic disease [7]. These programs also integrate a coaching plan, in which the health physician promotes patient empowerment for attaining treatment adherence and behavior modification [8]. For the coordination of integrated care programs, a clinical nurse specialist can play an important role [5].

In patients with heart failure and coronary heart disease, significant improvement has been observed due to the multidisciplinary approach [9,10]. The management of atrial fibrillation is often difficult due to lack of adherence to recommendations [11]. Such multidisciplinary plans are essential for the provision of guideline-based AF management with the collaboration of different physicians [5]. An AF program should include diagnostic tests, heart rate and rhythm control, anticoagulation, management of associated disorders, patient education and counseling for self-management [12].

The integrated healthcare methodology has backgrounds from the chronic healthcare model with the understanding that chronic disease management requires an unusual approach in contrast to standard usual models of healthcare delivery. This prototypical set- up gives the patient the principal emphasis, with various significant essentials/components, including a multidisciplinary team and supports from the community, to warrant that the patient population is dynamically engaged regarding their treatment. Augmenting patient-related consequences incorporating this delivery strategy is reached through redesigning usual clinical practice to confirm healthcare is provided tailor-made to the patient's requirements and founded on existing data [6].

There are five cornerstones of an effective multidisciplinary atrial fibrillation program. These are "comprehensive assessment, systematization of medical care, patient education, coordination of care and evaluation of care plan execution" [5]. A detailed assessment of the patient is essential for making a suitable management plan [13]. Systemization involves coordination of diagnostic work-up, treatment plan and follow-up [5]. Systemization of medical care will improve the excellence of care delivery, patient contentment and the use of means [14]. Patient education leads to dynamic patient involvement and adherence to treatment. An AF program must be effectively coordinated for the implementation of the management plan. The last and the most critical aspect is the evaluation of care plan execution [5]. The cornerstones of multidisciplinary atrial fibrillation program are shown in (Figure 1).

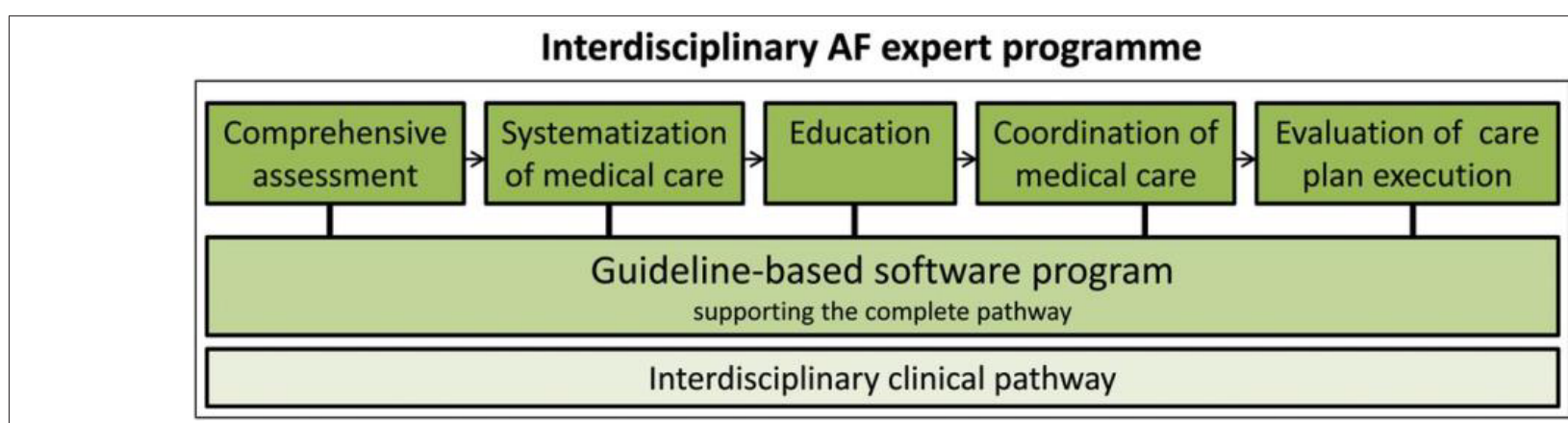

Figure 1: "Cornerstones of multidisciplinary atrial fibrillation program" [5]

This systematic review and meta-analysis were planned to access the effectiveness of multidisciplinary integrated care in the clinical outcomes of atrial fibrillation patients including all-cause mortality, MACE, cardiovascular deaths, cardiovascular \&AFrelated hospitalizations, cerebrovascular episodes and major \& minor bleeding. Evidence has established the need for integrated systems of healthcare delivery in various chronic cardiovascular afflictions, like heart failure and acute coronary syndrome, there is hardly any for the AF population. Lately, research papers have been probing the need for integrated healthcare in atrial fibrillation patients for further improvement and insight in the management of atrial fibrillation.

\section{Objective}

Atrial fibrillation (AF) is linked with substantial morbidity and mortality. Cardiovascular illnesses of chronic settings have shown improved patient specific outcomes from integrated structures of healthcare, the practice of this very methodology in atrial fibrillation patients is a relatively new idea. Current data has recommended that the integrated healthcare methodology may be of advantage in the AF population, still not broadly realized in routine medical management (Figure 2). 


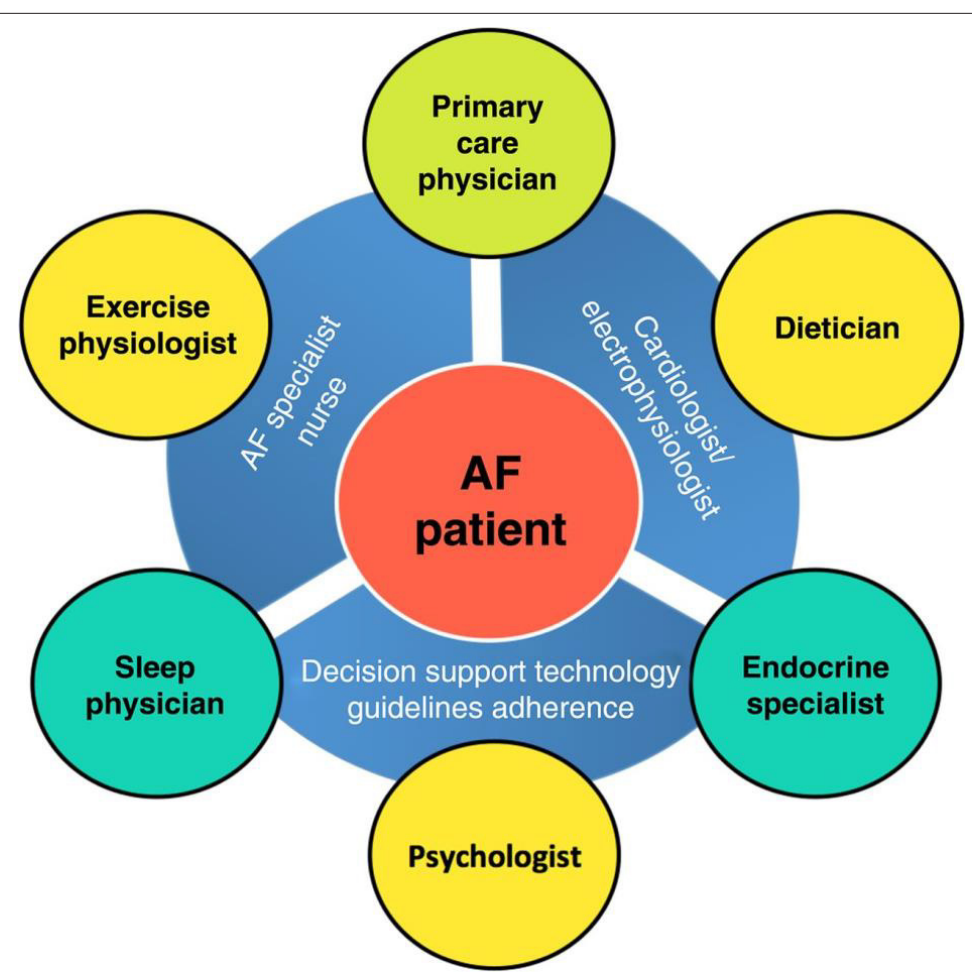

Figure 2: "The integrated care approach in atrial fibrillation (AF)" [33].

The aim of the systematic review and meta-analysis was to assess the effect of multidisciplinary integrated care systems of healthcare provision in the AF patient population on outcomes including all-cause mortality, MACE, cardiovascular deaths, cardiovascular \& AF-related hospitalizations, cerebrovascular episodes and major \& minor bleeding.

\section{Material and Methods}

Preferred Reporting Items for Systematic Reviews and Metaanalyses (PRISMA) guidelines were adhered for this systematic review and meta-analysis. The study is registered with PROSPERO International Prospective Register of Systematic Reviews (PROSPERO registration number CRD42018110613).

\section{Study design}

Systematic review and meta-analysis

\section{Eligibility criteria}

Studies were selected as per the following criteria:

Studies included were randomized controlled trials (RCTs), including cluster RCTs.

We excluded controlled (non-randomized) clinical trials (CCTs) or cluster trials, cross-sectional studies, case series, case reports, interrupted time series (ITS) studies, prospective and retrospective comparative cohort studies, and case-control or nested casecontrol studies.

\section{Participants}

Studies including the general adult human population (18 years or older) of either gender diagnosed with and treated for Atrial Fibrillation; defined as "recurrent paroxysmal, persistent, or permanent atrial fibrillation".

\section{Interventions}

Multidisciplinary integrated healthcare intervention, emphasis on all-inclusive and far-reaching AF treatment and management with at least a 6-month follow-up period. Intervention is defined as "a coordinated patient-centered approach by interdisciplinary specialists to improve AF outcomes" [15].

"Integrated care facilitates treatment of AF patient's population in all five spheres of management: acute stabilization, detection and management of primary cardiovascular co-morbidities and risk dynamics, apposite oral anticoagulation for stroke prevention, and treatment with rate and/or rhythm control therapy" $[11,16]$ (Figure 3). 


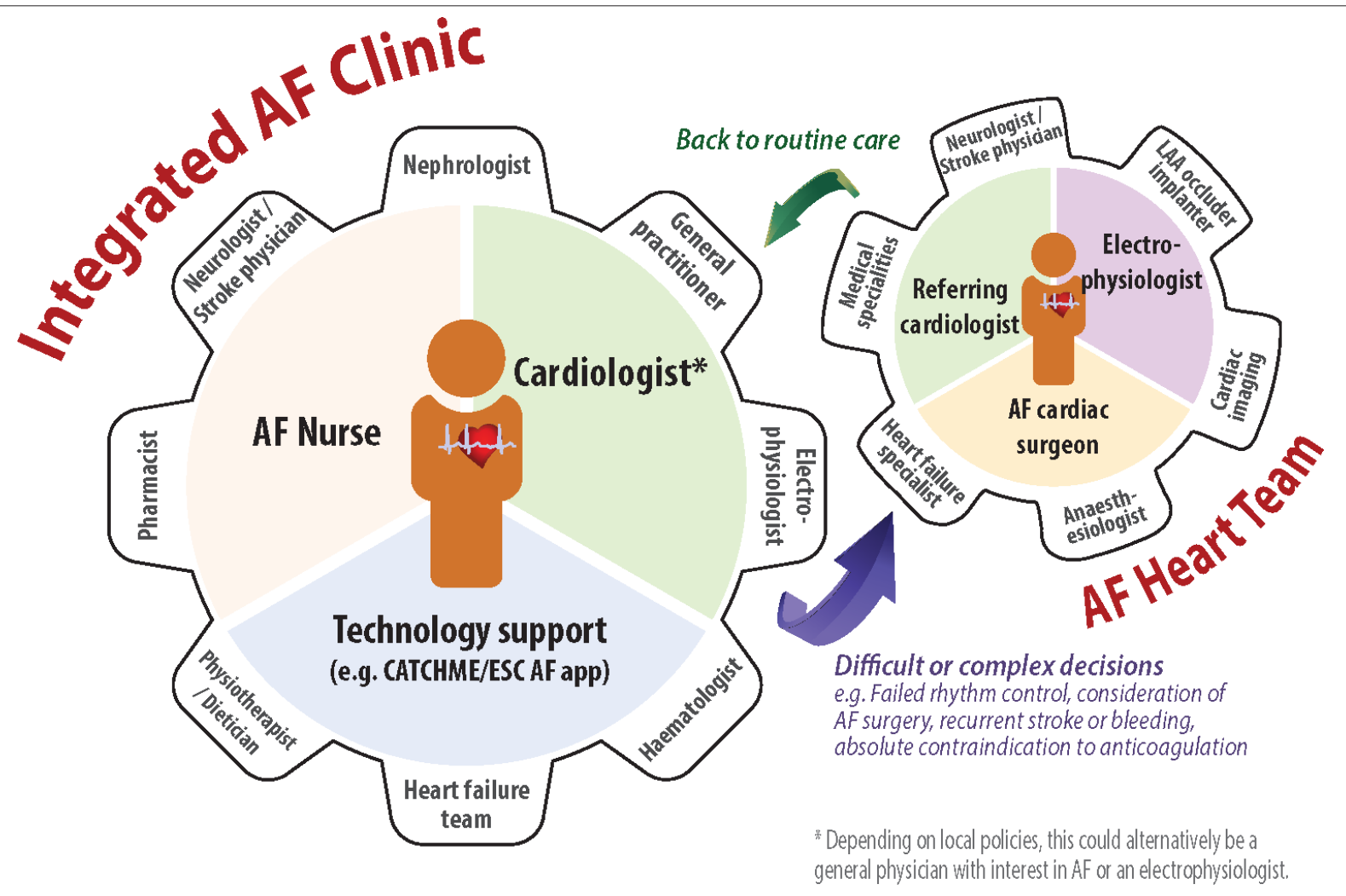

Figure 3: "Integrated AF care and AF heart team" [15].

\section{Comparators}

The patients in the comparator group were treated according to the usual standards of clinical care, regular medical care, outpatient management and pharmacotherapy. The management was Not Integrated or Multidisciplinary.

\section{Outcomes}

The major outcomes/endpoints for meta-analysis were MACE; major adverse cardiovascular event(s) and/or NACE; net adverse clinical event(s)
a. All-cause mortality
b. Cardiovascular mortality
c. AF- related hospitalization
d. Cardiovascular hospitalization
e. MACE
f. Major Bleeding \& Minor Bleeding
g. Cerebrovascular accidents(stroke)

\section{Timing}

Studies inclusion was based on the follow-up of outcomes. For all endpoint outcomes, RCTs had a follow-up time of at least 06 months with further analysis at follow-up of 01 year.

\section{Setting}

Any kind of setting with no restrictions

\section{Language}

Included RCTs reported in the English language only

\section{Information sources}

Medical Literature search strategies were devised using medical subject headings (MeSH) and text words linked to atrial fibrillation. The articles were searched on MEDLINE (PubMed and OVID interface, 1948 onwards till 2017), EMBASE (OVID interface, 1974 onwards till 2017), and the Cochrane Central Register of Controlled Trials (Wiley interface). The scientific literature search was limited to the English language and human subjects.

\section{Search strategy}

Medline, EMBASE, and the CENTRAL trials registry of the Cochrane Collaboration were searched for keywords, including 'atrial fibrillation', 'integrated healthcare', 'multidisciplinary', 'outpatient', 'interdisciplinary', 'treatment outcome', 'treatment adherence, 'death', 'mortality', 'fatal', 'hospitalization', 'hospital admissions', 'quality of life' and 'symptom burden'. 


\section{Data management, selection process and data collection}

Investigators individually evaluated all pertinent articles to categorize studies meeting criteria for inclusion. Any inconsistencies were deliberated and a consensus verdict was obtained. The search results from each database were saved in EndNote X9 and duplicates were removed.

\section{Data items}

Data was extracted into a standard recording form (Microsoft EXCEL datasheet) which was initially tried to confirm clarity and uniformity between authors. This empowers the authors to evaluate the quality of studies and integrate the findings. Data identified and tabulated from appropriate articles included: author, data collection year, publication year, participants, gender, mean age, follow-up duration and outcomes studied.

\section{Outcomes and prioritizations}

Outcomes that were extracted from the selected studies included all-cause mortality, cardiovascular mortality, MACE, cerebrovascular accidents, major and minor bleeding.

\section{Data synthesis}

A quantitative synthesis of data and meta-analysis was conducted for selected studies with similar study design and sufficient available outcome parameters to perform a statistical analysis using the STATA/SE 15.0 statistical program (StataCorp, Texas, USA).

Assuming a variation of the true effect sizes in the selected studies - due to different study populations and different integrated care models (as obvious in many integrated care models), we chose to perform a random-effect meta-analysis model to gain the pooled estimates of effects. For the summary statistics, we used exclusively dichotomous data and results were expressed by using odds ratio (OR) with 95\% confidence interval (CI). A two-tailed value of $\mathrm{p}<0.05$ was considered statistically significant. The presence of publication bias was visually assessed using funnel plots of effect size against SE. Non-quantitative data was presented descriptively. To test statistical heterogeneity between the studies, the chi-square $(\chi 2)$ test and the $\mathrm{I}^{2}$ statistic were applied. If a high level of heterogeneity was detected $\left(\mathrm{I}^{2}>=50 \%\right)$, a narrative synthesis of studies will be appropriate (Figure 4).

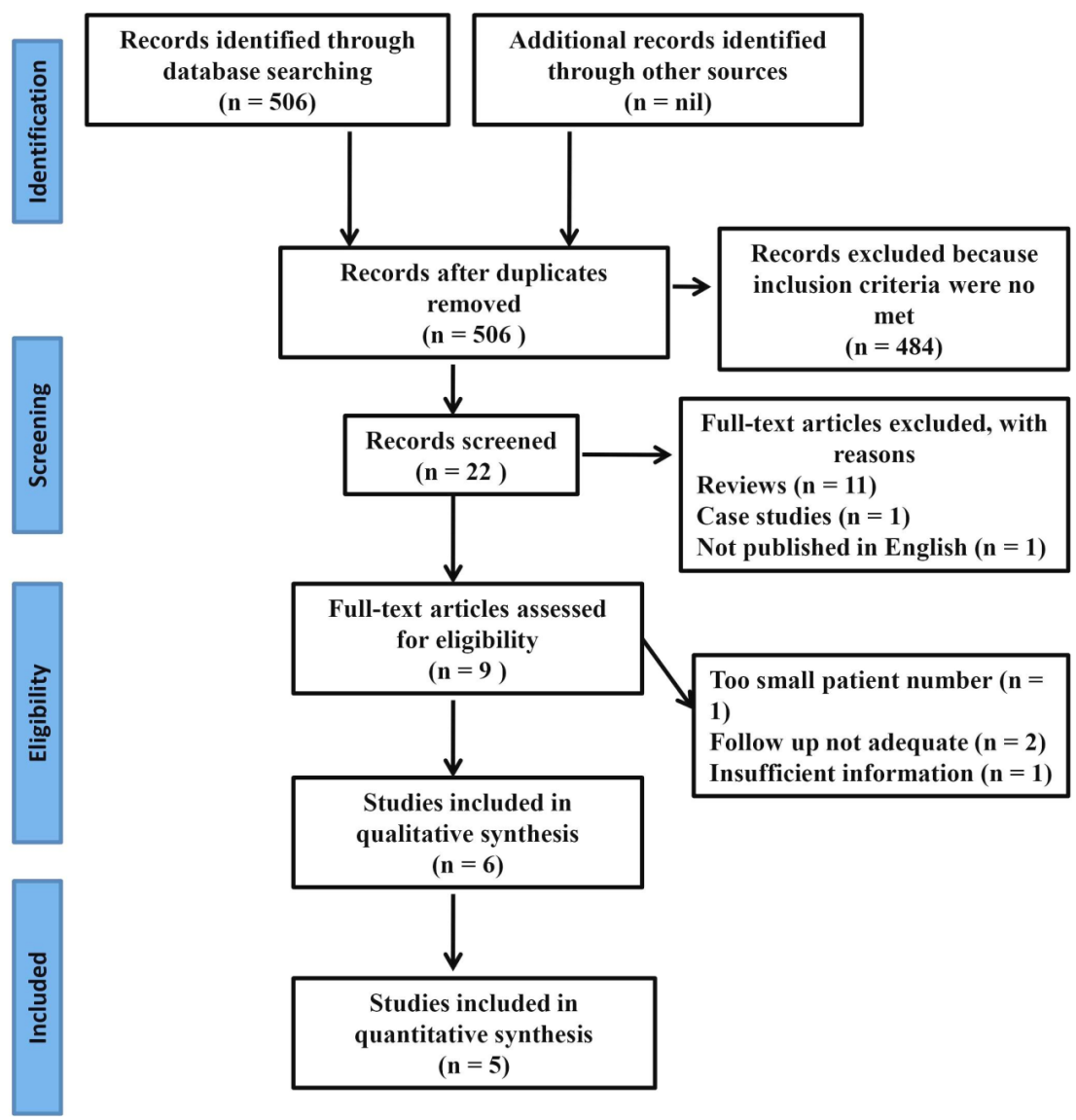

Figure 4: PRISMA flow diagram. 


\section{Risk of bias individual studies}

Cochrane Collaboration tool (The RoB 2.0 tool http://www. riskofbias.info/) was used to assess the risk of bias for every RCT, which screens: randomization process, deviation from intended intervention, missing outcome data and selective result reporting (Table 1).

\begin{tabular}{|c|c|c|c|c|c|c|}
\hline Study & $\begin{array}{l}\text { Randomization } \\
\text { process }\end{array}$ & $\begin{array}{l}\text { Deviation from intended } \\
\text { interventions }\end{array}$ & $\begin{array}{c}\text { Missing } \\
\text { outcome data }\end{array}$ & $\begin{array}{l}\text { Measurement } \\
\text { of outcome }\end{array}$ & $\begin{array}{l}\text { Selection of the } \\
\text { reported result }\end{array}$ & Overall bias \\
\hline Hendriks, EHJ 2012 & Low & Low & Low & Low & Low & Low \\
\hline Stewart, Lancet 2015 & Low & Low & Low & Low & Low & Low \\
\hline Carter, JAHA 2016 & Some concern & Low & Low & Low & Low & Some concern \\
\hline Vinereanu, Lancet 2017 & Low & Low & Low & Low & Low & Low \\
\hline Fuenzalida, IEN 2017 & Some concern & Low & Low & Low & Low & Some concern \\
\hline
\end{tabular}

\section{Results}

The search generated an aggregate of 506 articles that were evaluated by title and abstract. Four eighty four articles were excluded as they did not fulfill the inclusion criteria. Nine articles were examined for full-text assessment with five fulfilling the criteria for inclusion in the meta-analysis. Primary and secondary outcomes, as shown in table 2 below, are tabulated for easy reference and the selection for qualitative and quantitative analysis marked as per the formal inclusion/exclusion criteria.

Key characteristics of the various studies screened, shortlisted and selected are tabulated in (Tables 2 and 3 ).

Parameters that were obtained from the studies included for meta-analysis were all-cause mortality, MACE, cardiovascular mortality, cardiovascular hospitalizations, AF-related hospitalizations, cerebrovascular events (stroke) and major \& minor bleeding episodes.

Table 2: Characteristics of studies included in the systematic review and meta-analysis.

\begin{tabular}{|c|c|c|c|c|c|c|c|c|c|c|c|}
\hline $\begin{array}{l}\text { Study/ } \\
\text { Author }\end{array}$ & Year & Journal & $\begin{array}{l}\text { Study } \\
\text { Type }\end{array}$ & $\begin{array}{c}\text { No. of } \\
\text { pa- } \\
\text { tients }\end{array}$ & $\begin{array}{l}\text { Recruitment } \\
\text { method }\end{array}$ & Intervention & $\begin{array}{l}\text { Follow- } \\
\text { up }\end{array}$ & $\begin{array}{l}\text { Primary } \\
\text { outcome }\end{array}$ & $\begin{array}{l}\text { Secondary } \\
\text { outcome }\end{array}$ & $\begin{array}{l}\text { Sys- } \\
\text { tematic } \\
\text { review }\end{array}$ & $\begin{array}{l}\text { Meta- } \\
\text { analysis } \\
\text { (Clinical } \\
\text { events) }\end{array}$ \\
\hline Inglis [25] & 2004 & $\begin{array}{c}\text { J } \\
\text { Cardiovasc } \\
\text { Nurs }\end{array}$ & $\begin{array}{l}\text { RCT / } \\
\text { Sub } \\
\text { group of } \\
\text { bigger } \\
\text { RCT }\end{array}$ & 152 & $\begin{array}{l}\text { Hospital } \\
\text { admission } \\
\text { with AF }\end{array}$ & Integrated care & 5 years & $\begin{array}{l}\text { Readmission and } \\
\text { mortality }\end{array}$ & & $\sqrt{ }$ & \\
\hline $\begin{array}{l}\text { Hendriks } \\
\text { [12] }\end{array}$ & 2012 & Eur Heart J & RCT & 712 & $\begin{array}{l}\text { Referred to } \\
\text { outpatient AF } \\
\text { clinic }\end{array}$ & $\begin{array}{c}\text { Nurse-led } \\
\text { integrated care }\end{array}$ & $\begin{array}{c}12 \\
\text { months }\end{array}$ & $\begin{array}{c}\text { Cardiovascular } \\
\text { hospitalization } \\
\text { and } \\
\text { cardiovascular } \\
\text { death }\end{array}$ & & $\sqrt{ }$ & $\sqrt{ }$ \\
\hline $\begin{array}{l}\text { Hendriks } \\
\text { [21] }\end{array}$ & 2014 & Europace & RCT & 712 & $\begin{array}{l}\text { Referred to } \\
\text { outpatient AF } \\
\text { clinic }\end{array}$ & $\begin{array}{c}\text { Nurse- led } \\
\text { integrate d care }\end{array}$ & $\begin{array}{c}12 \\
\text { months }\end{array}$ & $\begin{array}{l}\text { Quality of life } \\
\text { (QoL) }\end{array}$ & & & \\
\hline $\begin{array}{c}\text { Stewart } \\
\text { [22] }\end{array}$ & 2015 & Lancet & RCT & 335 & $\begin{array}{l}\text { Hospital } \\
\text { admission } \\
\text { with AF }\end{array}$ & $\begin{array}{c}\text { Nurse follow } \\
\text { up + holter ECG } \\
\text { Multidisciplinary } \\
\text { approach }\end{array}$ & $\begin{array}{l}12 \text { and } 24 \\
\text { months }\end{array}$ & $\begin{array}{c}\text { Death or } \\
\text { unplanned } \\
\text { readmission } \\
\text { (both all-cause) }\end{array}$ & $\begin{array}{l}\text { Unplanned, } \\
\text { cardiovascular } \\
\text { specific and } \\
\text { all-cause } \\
\text { readmission } \\
\text { and length of } \\
\text { hospital stay }\end{array}$ & $\sqrt{ }$ & $\sqrt{ }$ \\
\hline $\begin{array}{c}\text { Carter } \\
\text { [16] }\end{array}$ & 2016 & $\begin{array}{c}\text { J Am Heart } \\
\text { Ass }\end{array}$ & $\begin{array}{c}\text { Before/ } \\
\text { After }\end{array}$ & 413 & $\begin{array}{l}\text { Presented to } \\
\text { ED with AF }\end{array}$ & $\begin{array}{l}\text { Nurse- led } \\
\text { education and } \\
\text { supervise d }\end{array}$ & $\begin{array}{c}12 \\
\text { months }\end{array}$ & $\begin{array}{c}\text { Death, } \\
\text { cardiovascular } \\
\text { hospitalization, } \\
\text { AF-related } \\
\text { emergency } \\
\text { department visits }\end{array}$ & $\begin{array}{c}\text { Primary } \\
\text { outcome + } \\
\text { stroke + major } \\
\text { and minor } \\
\text { bleeding + } \\
\text { adherence to } \\
\text { Medication }\end{array}$ & $\sqrt{ }$ & $\sqrt{ }$ \\
\hline $\begin{array}{c}\text { Fuenzalid } \\
\text { [23] }\end{array}$ & 2017 & $\begin{array}{l}\text { Int Emergn } \\
\text { Nurs }\end{array}$ & RCT & 240 & $\begin{array}{l}\text { Patients } \\
\text { with AF } \\
\text { discharged } \\
\text { from ER }\end{array}$ & Nurse education & $\begin{array}{c}12 \\
\text { months }\end{array}$ & $\begin{array}{l}\text { AF- or treatment- } \\
\text { related } \\
\text { complications or } \\
\text { death }\end{array}$ & $\begin{array}{c}\text { AF-related), } \\
\text { admissions } \\
\text { (global and AF- } \\
\text { or death }\end{array}$ & & $\sqrt{ }$ \\
\hline
\end{tabular}




\begin{tabular}{|c|c|c|c|c|c|c|c|c|c|c|c|}
\hline $\begin{array}{l}\text { Vinereanu } \\
{[24]}\end{array}$ & 2017 & Lancet & $\begin{array}{l}\text { Cluster } \\
\text { RCT }\end{array}$ & 2276 & $\begin{array}{l}\text { Patients with } \\
\text { AF from } 5 \\
\text { countries }\end{array}$ & $\begin{array}{l}\text { Nurse led } \\
\text { educational } \\
\text { approach }\end{array}$ & $\begin{array}{c}12 \\
\text { months }\end{array}$ & $\begin{array}{l}\text { Adherence to oral } \\
\text { anticoagulants } \\
\text { (OAC) }\end{array}$ & $\begin{array}{c}\text { Clinical } \\
\text { outcomes } \\
\text { (death, stroke...) }\end{array}$ & $\sqrt{ }$ & $\sqrt{ }$ \\
\hline $\begin{array}{c}\text { Bowyer } \\
{[26]}\end{array}$ & 2017 & $\begin{array}{l}\text { Heart Lung } \\
\quad \text { Circ }\end{array}$ & RCT & 41 & $\begin{array}{l}\text { Patients } \\
\text { with AF } \\
\text { undergoing } \\
\text { first catheter } \\
\text { ablation }\end{array}$ & $\begin{array}{l}\text { Nurse-led } \\
\text { education }\end{array}$ & 6 months & $\begin{array}{l}\text { Quality of life } \\
\text { (QoL) }\end{array}$ & $\begin{array}{l}\text { QoL (SF-36) and } \\
\text { hospitalization } \\
\text { due to AF }\end{array}$ & & \\
\hline $\begin{array}{l}\text { Hendriks } \\
\text { [27] }\end{array}$ & 2013 & Europace & RCT & 712 & $\begin{array}{l}\text { Referred to } \\
\text { outpatient AF }\end{array}$ & $\begin{array}{c}\text { Nurse- led } \\
\text { integrated care }\end{array}$ & $\begin{array}{c}12 \\
\text { months }\end{array}$ & $\begin{array}{c}\text { QALY (cost } \\
\text { effectiveness) }\end{array}$ & & & \\
\hline
\end{tabular}

Table 3: Parameters of included studies.

\begin{tabular}{|c|c|c|c|c|c|}
\hline Study Parameters & Hendriks & Stewart & Carter & Fuenzalida & Vinereanu \\
\hline Number of Participants & 712 & 335 & 413 & 240 & 2276 \\
\hline Integrated care group & 356 & 168 & 185 & 116 & 1184 \\
\hline Usual care group & 356 & 167 & 228 & 124 & 1092 \\
\hline Mean Age & 66.5 & 72 & 64 & 76.1 & 69.5 \\
\hline Integrated care group & 66 & 72 & 64 & 74.8 & 70 \\
\hline Usual care group & 67 & 71 & 64 & 77.3 & 69 \\
\hline Female Gender & $294 / 712$ & $161 / 335$ & $174 / 413$ & $138 / 240$ & $1079 / 2276$ \\
\hline Integrated care group & $159 / 356$ & $84 / 168$ & $71 / 185$ & $67 / 116$ & $571 / 1184$ \\
\hline Usual care group & $135 / 356$ & $77 / 167$ & $103 / 228$ & $71 / 124$ & $508 / 1092$ \\
\hline \multicolumn{6}{|c|}{ Composite Endpoint } \\
\hline Integrated care group & $51 / 356$ & $127 / 168$ & $29 / 185$ & $37 / 116$ & $22 / 1184$ \\
\hline Usual care group & $74 / 356$ & $137 / 167$ & $44 / 228$ & $60 / 124$ & $29 / 1092$ \\
\hline \multicolumn{6}{|c|}{ All-cause Mortality } \\
\hline Integrated care group & $13 / 356$ & $19 / 168$ & $0 / 185$ & $26 / 116$ & $62 / 1184$ \\
\hline Usual care group & $29 / 356$ & $30 / 167$ & $1 / 228$ & $43 / 124$ & $56 / 1092$ \\
\hline \multicolumn{6}{|c|}{ Cardiovascular Death } \\
\hline Integrated care group & $4 / 356$ & & & $18 / 116$ & \\
\hline Usual care group & $14 / 356$ & & & $26 / 124$ & \\
\hline \multicolumn{6}{|c|}{ Cardiovascular Hospitalization } \\
\hline Integrated care group & $48 / 356$ & & $10 / 185$ & $31 / 116$ & \\
\hline Usual care group & $68 / 356$ & & $16 / 228$ & $43 / 124$ & \\
\hline \multicolumn{6}{|c|}{ AF-related Hospitalization/ED visits } \\
\hline Integrated care group & $15 / 356$ & $54 / 168$ & $22 / 185$ & & \\
\hline Usual care group & $23 / 356$ & $57 / 167$ & $35 / 228$ & & \\
\hline \multicolumn{6}{|c|}{ Stroke } \\
\hline Integrated care group & $3 / 356$ & $8 / 168$ & $4 / 185$ & $3 / 116$ & $11 / 1184$ \\
\hline Usual care group & $5 / 356$ & $6 / 167$ & $4 / 228$ & $3 / 124$ & $21 / 1092$ \\
\hline \multicolumn{6}{|c|}{ Major Bleeding } \\
\hline Integrated care group & $6 / 356$ & & $0 / 185$ & & 9/1184 \\
\hline Usual care group & $6 / 356$ & & $3 / 228$ & & $7 / 1092$ \\
\hline \multicolumn{6}{|c|}{ Bleeding (Major +Minor) } \\
\hline Integrated care group & & $25 / 168$ & $3 / 185$ & $13 / 116$ & $49 / 1184$ \\
\hline Usual care group & & $23 / 167$ & $6 / 228$ & $13 / 124$ & $38 / 1092$ \\
\hline \multicolumn{6}{|c|}{ Oral Anticoagulant Use } \\
\hline Integrated care group & & & & & $943 / 1184$ \\
\hline Usual care group & & & & & $732 / 1092$ \\
\hline
\end{tabular}




\section{All-cause mortality}

Data of all-cause mortality was provided in five studies included in the meta-analysis with an acceptable heterogeneity among the studies $\left(\mathrm{I}^{2}=45.5 \%, \mathrm{p}=0.119\right)$ which showed a significant $35 \%$ reduction of all-cause mortality in the integrated care model (OR $0.65,95 \%$ CI 0.44 to $0.95 ; \mathrm{p}=0.028$ ) (Figure 5).

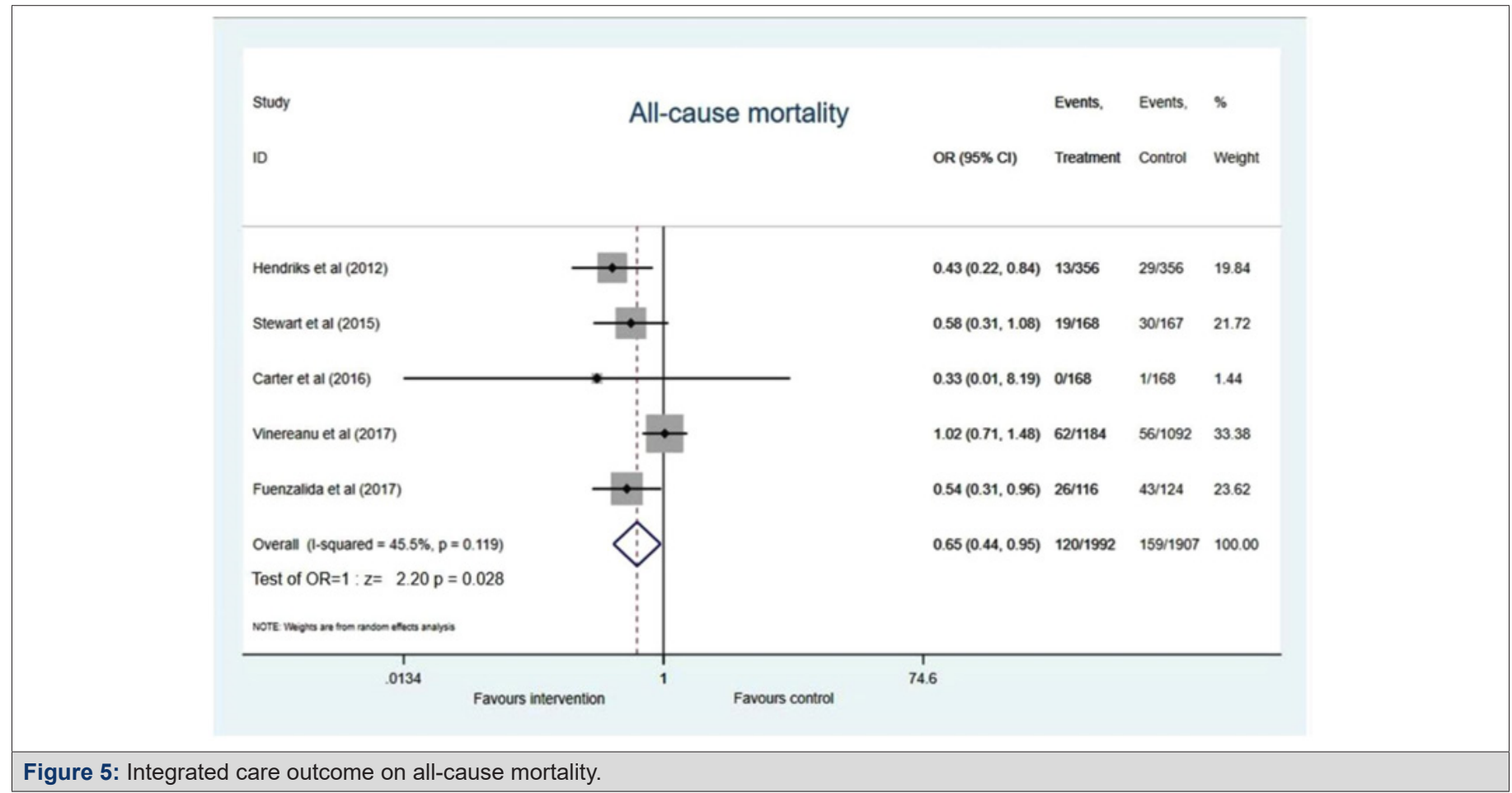

\section{Major adverse cardiovascular event (MACE)}

Five studies reported on this outcome. There was a significant reduction of MACE in favor of the integrated care approach (OR 1.39, 95\% CI 1.19-1.62, p-value 0.000; I-squared > 0.05). No evidence of significant heterogeneity $\left(\mathrm{I}^{2}=32 \%, \mathrm{p}=0.208\right)$ (Figure 6).

\section{Cardiovascular mortality}

Two studies reported on this outcome, favoured integrated care (OR $0.49,95 \% \mathrm{CI} 0.21$ to $1.17, \mathrm{p}=0.109$ ). But the result was not statistically significant as only 2 studies reported this outcome. Significant heterogeneity not established $\left(I^{2}=47.1 \%, p=0.169\right)$ (Figure 7).

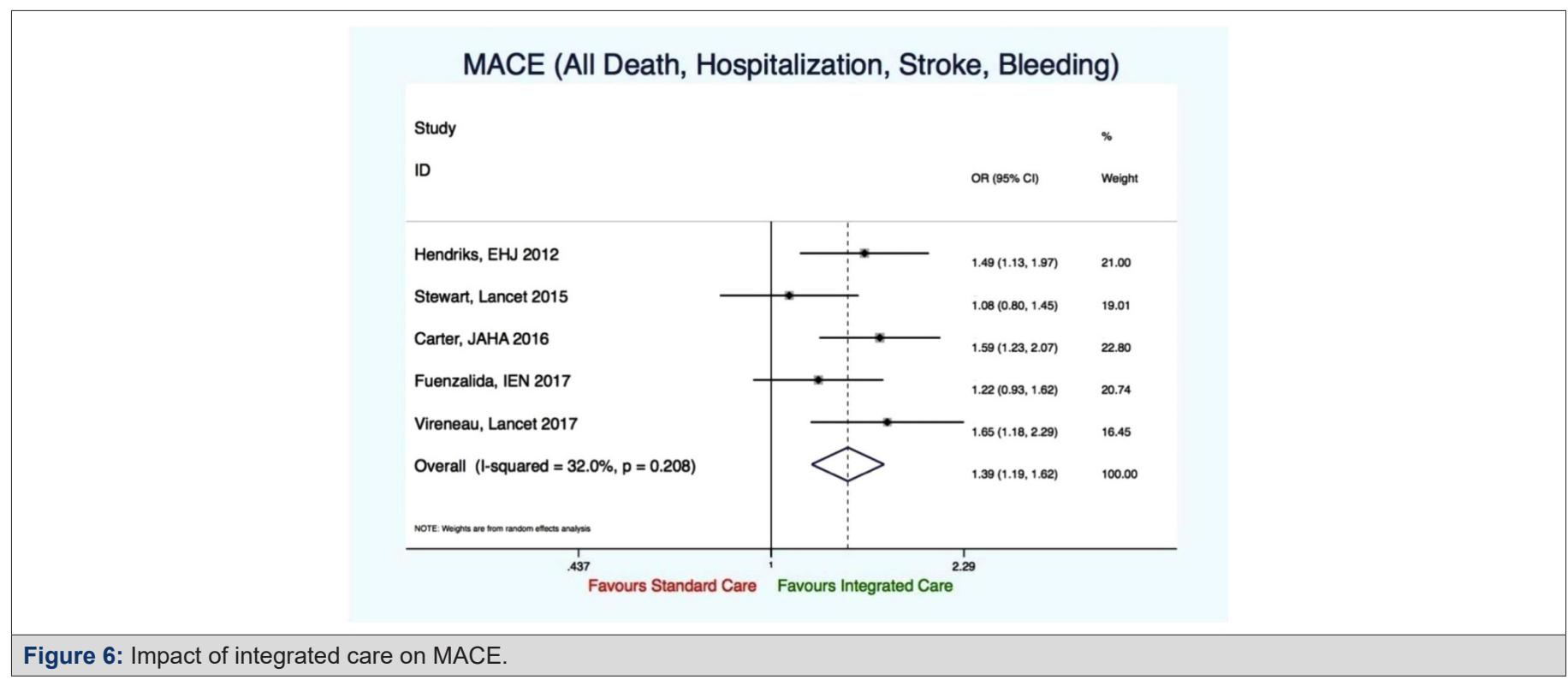




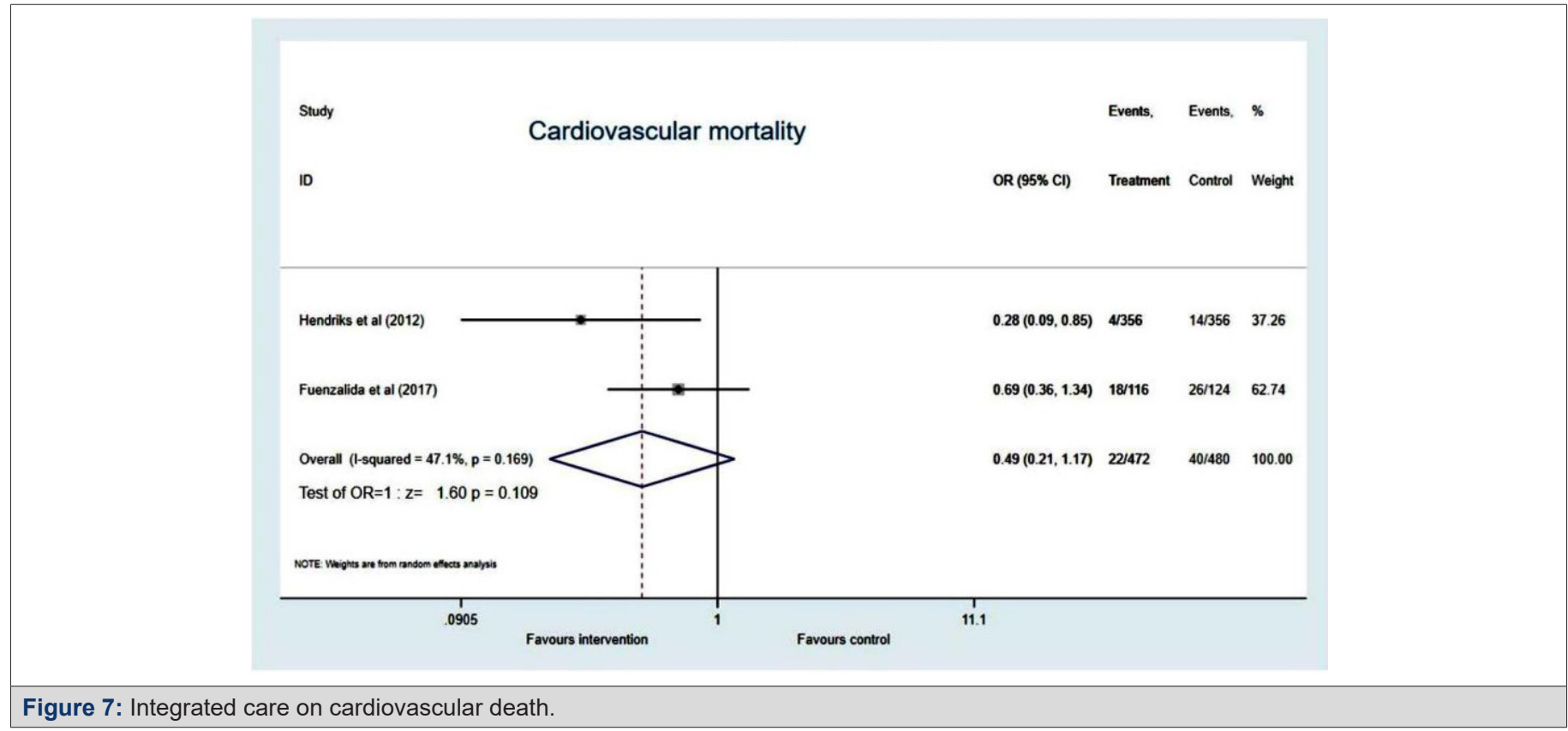

\section{AF-related hospitalization}

Three studies reported about AF-related hospitalization. AFrelated hospitalization had not been significantly influenced by the integrated care model, however, there was a trend favoring the integrated care approach (OR 1.36, 95\% CI 0.99 to 1.87; p=0.056), no evidence for heterogeneity could be observed $\left(\mathrm{I}^{2}=0.0 \%\right.$, $\mathrm{p}=0.414$ ) (Figure 8).

\section{Cardiovascular hospitalization}

Three studies reported cardiovascular hospitalization. The integrated care approach led to a significant 34\% reduction of CV hospitalization compared to standard care (OR 0.66, 95\% CI 0.49 to 0.89; $\mathrm{p}=0.007)$, see Figure 4. No heterogeneity between studies was observed $\left(I^{2}=0.0 \%, p=0.966\right)$ (Figure 9 ).

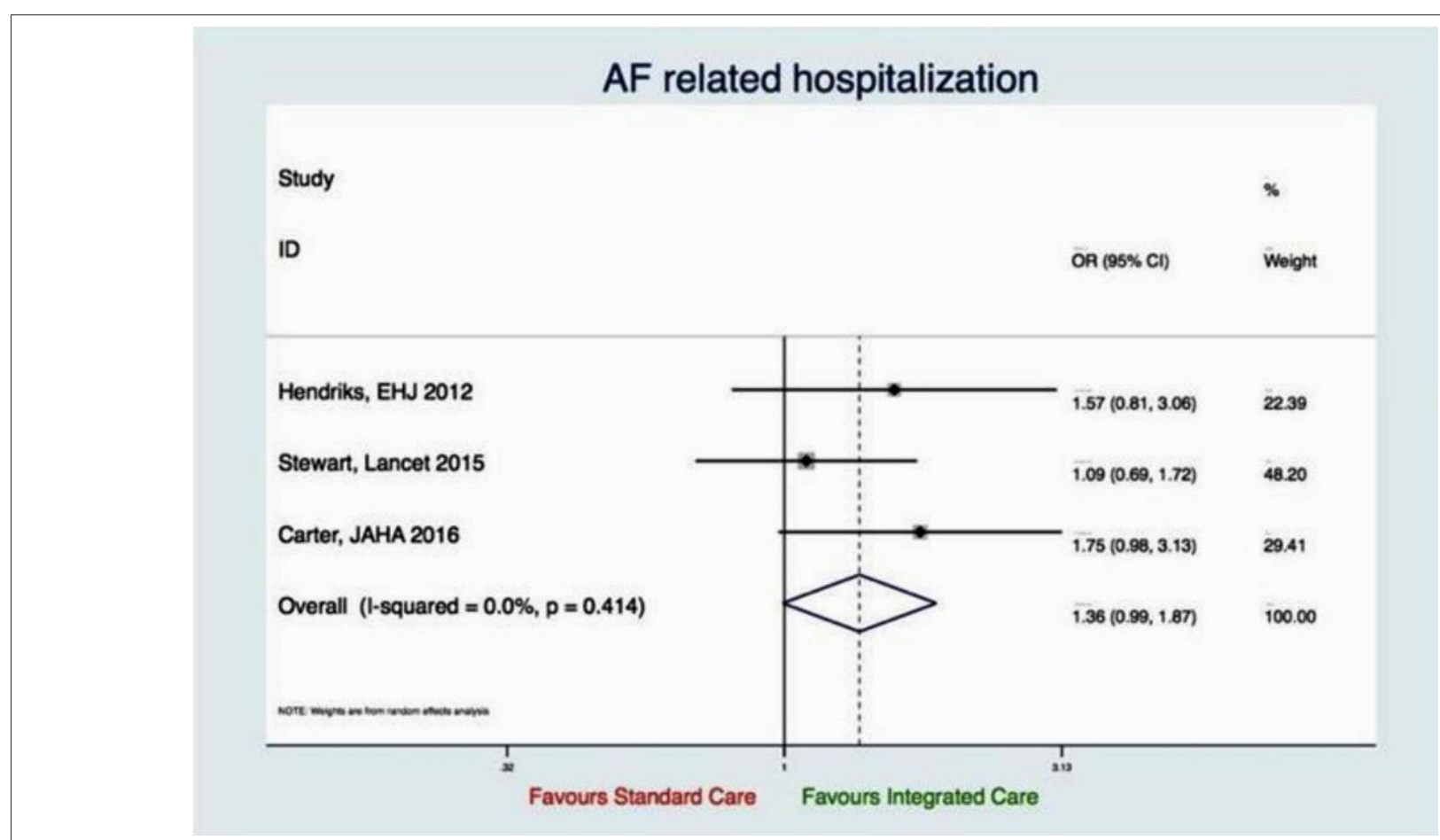

Figure 8: Integrated care on AF-related hospitalization. 


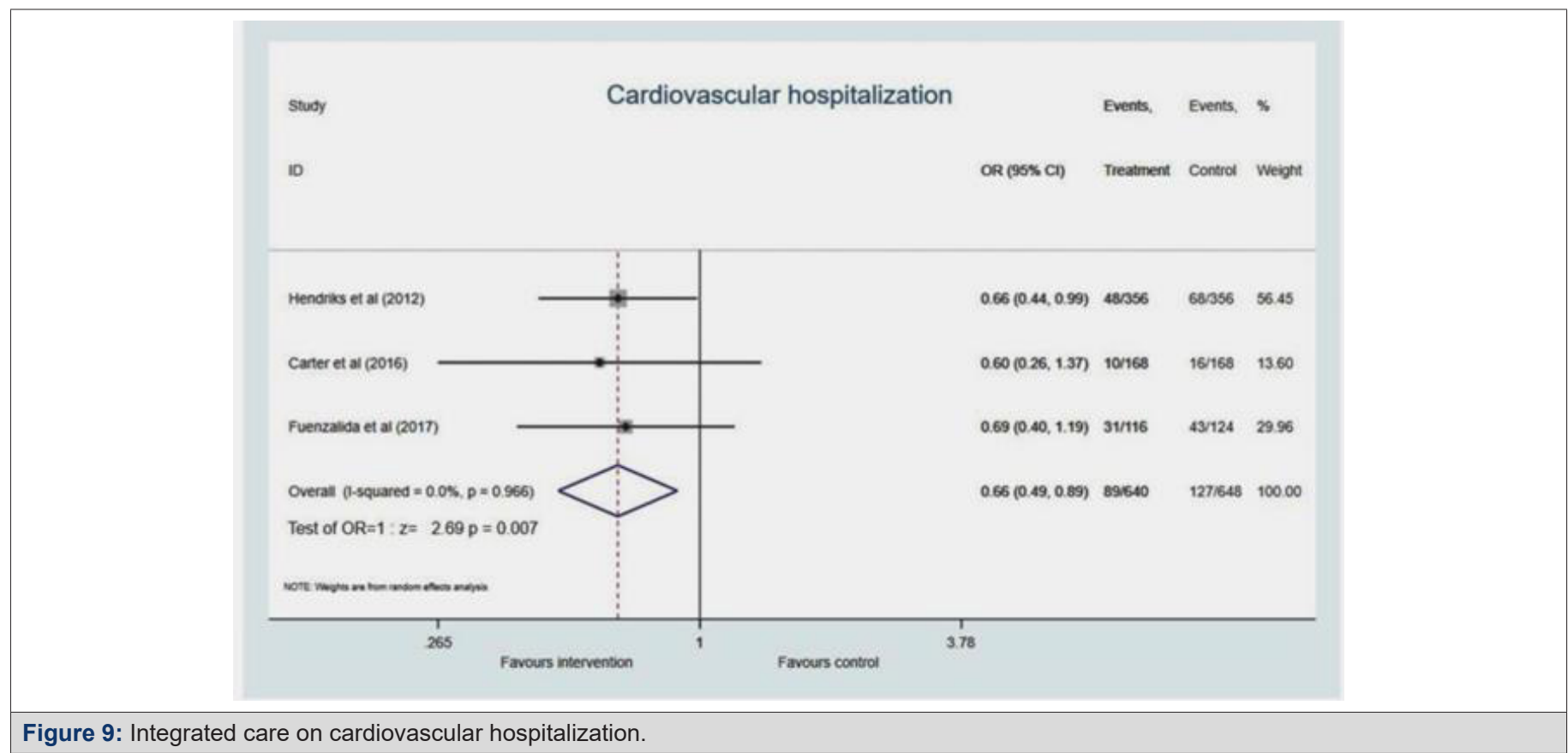

\section{Major bleeding}

Four studies reported on this outcome didn't favour integrated care or the standard care (OR 1.02, 95\%CI 0.59 to $1.75, \mathrm{p}=0.945$ ). No significant heterogeneity $\left(\mathrm{I}^{2}=0 \%, \mathrm{p}=0.610\right)$ (Figure 10 ).

\section{Minor bleeding}

Four studies reported on this outcome, didn't favour integrated care or standard care (OR 0.90, 95\%CI0.66 to $1.24, \mathrm{p}=0.52$ ). Evidence of significant heterogeneity not established $\left(\mathrm{I}^{2}=0 \%\right.$, $\mathrm{p}=0.691$ ) (Figure 11).

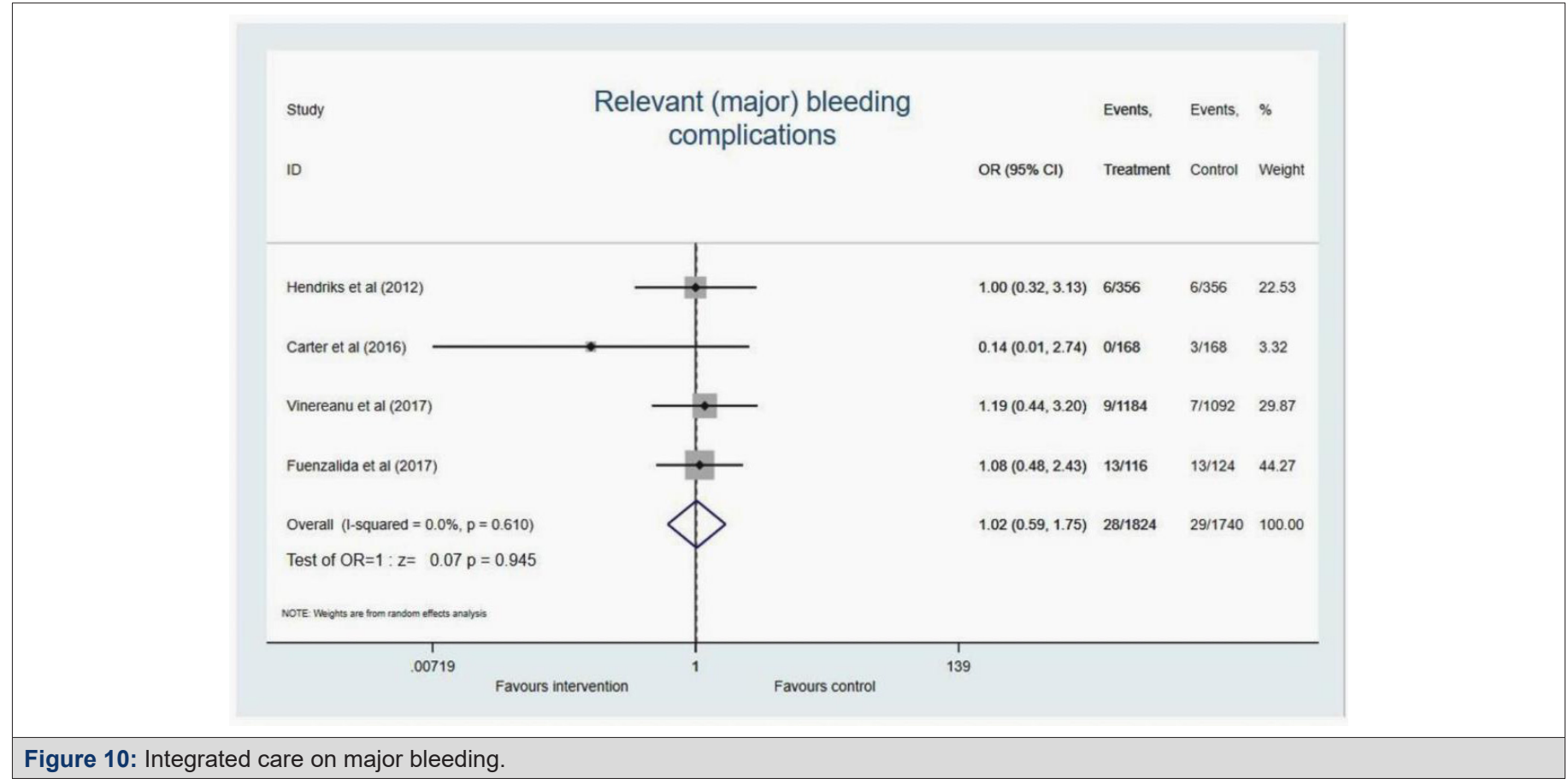




\section{Minor Bleeding}

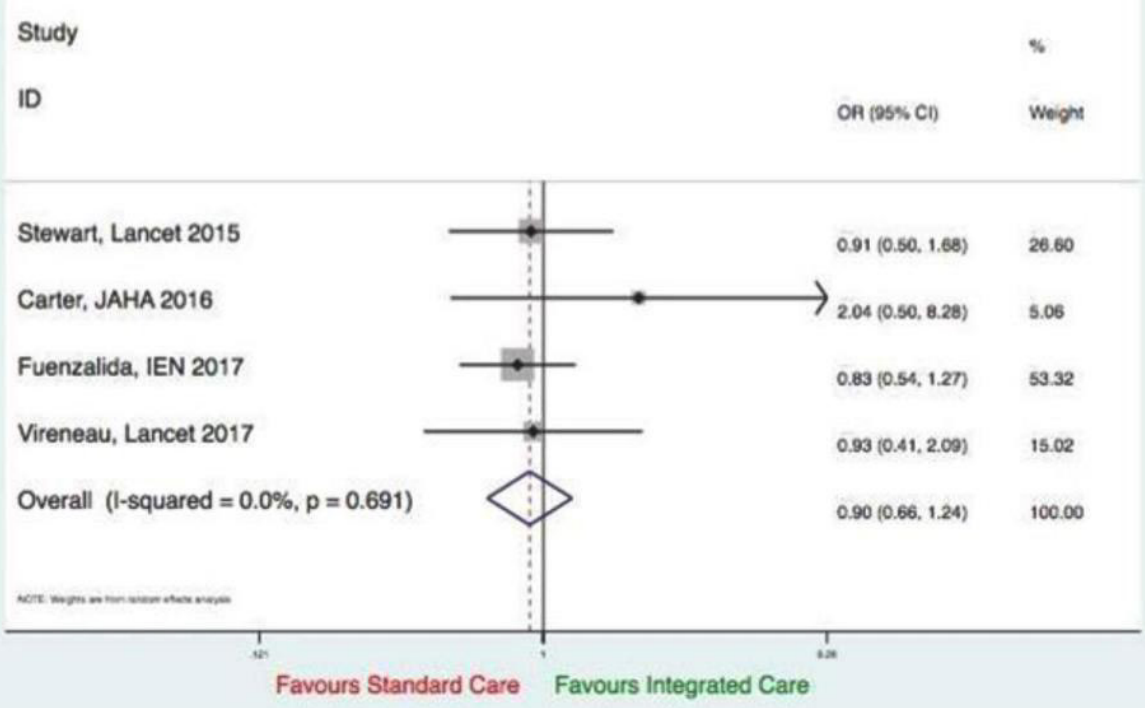

Figure 11: Integrated care on minor bleeding.

\section{Cerebrovascular events (stroke)}

Five studies reported on this outcome. There was no significant evidence in favour of integrated care (OR 1.38, 95\% CI 0.84 to 2.27 , $\mathrm{p}=0.20$ ) and there was no evidence of significant heterogeneity $\left(\mathrm{I}^{2}=0 \%, \mathrm{p}=0.573\right.$ ) (Figure 12).

Multidisciplinary integrated care versus educational integrated care

Studies reporting on this outcome, didn't favour significantly multidisciplinary integrated care over educational integrated care (OR 1.38, 95\%CI 1.22 to 1.56, Chi-Square $\mathrm{p}<0.05$ ). No heterogeneity $\left(\mathrm{I}^{2}=0.0 \%, \mathrm{p}=0.832\right)$ (Figure 13).

\section{MACE according to different studies characteristics}

Studies reporting on this outcome; parameters used were age, heart failure population, diabetes, use of oral anticoagulants; favoured integrated care (OR 4.00, 95\%CI 2.23 to 7.17, p=0.015). There was obvious heterogeneity due to subgroup analysis $\left(I^{2}=97.6 \%, p=0.000\right)$ (Figure 14).

\begin{tabular}{|l|l|l|l|l|}
\hline & \\
\hline
\end{tabular}




\section{MACE according to different studies}

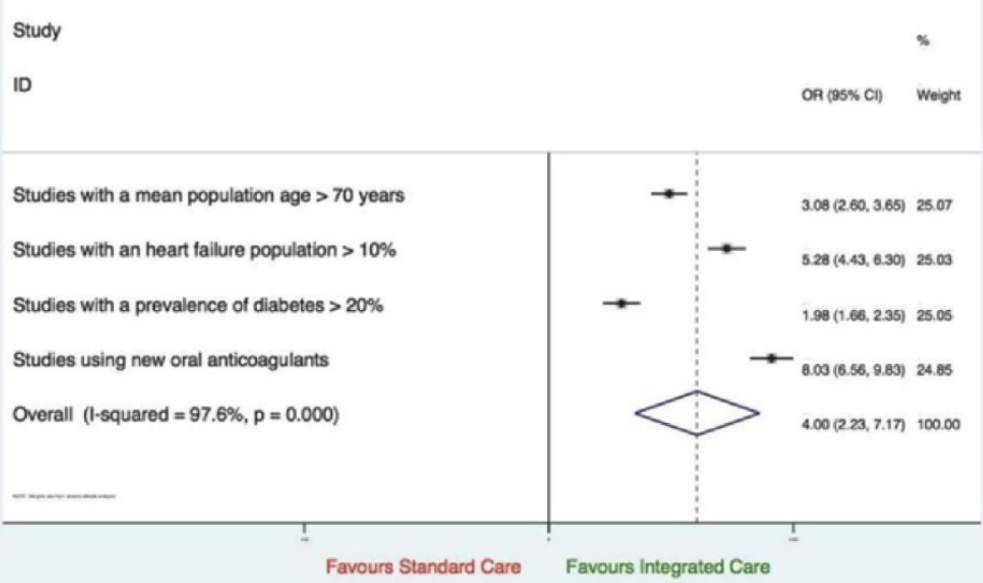

Figure 13: Multidisciplinary integrated care versus educational integrated care.

\section{MACE according to different studies}

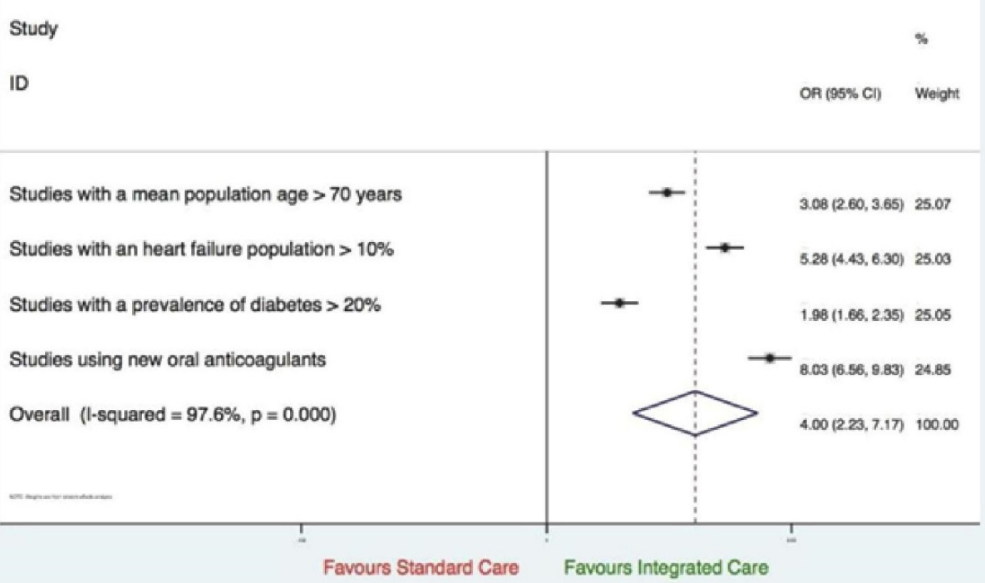

Figure 14: MACE According to Different Studies Characteristics.

\section{Discussion}

The meta-analysis of research studies estimating the importance of a multidisciplinary integrated care management in atrial fibrillation patients establishes that this intervention forms the basis of:

a) Enhanced patient health consequences, resulting from a decrease in all-cause mortality, cardiovascular mortality \& hospitalization, AF-related hospitalization and MACE

b) Insignificant influence of integrated care on the incidence of major or minor bleeding and cerebrovascular accidents

c) Educational and multidisciplinary integrated approach had similar outcomes d) There are subpopulations (older AF patients with heart failure and diabetes) who can benefit from an integrated approach.

These outcomes have meaningful inference on integrated healthcare delivery in atrial fibrillation patients and advocate its practice as an applicable and effectual intervention. Nevertheless, several queries remain unrequited and additional exploration is requisite to report how provision of this methodology is applied in the best possible manner and approach.

Integration and collaboration between outpatient \& inpatient departments and physicians play a vital role in the provision of excellent patient care [17]. The multidisciplinary approach has become increasingly important in the last few decades as a result of advancements in diagnostic and therapeutic techniques [18]. 
The purpose of integrated care is to strengthen the coordination in healthcare organizations, enhance the patients' experience, clinical outcomes and upgrade the efficiency of health systems [19].

A meta-analysis was done by Gallagher et al. to evaluate the role of integrated care in atrial fibrillation patients. The inclusion criteria were randomized and non-randomized studies on integrated care in $\mathrm{AF}$ patients with the control group and a minimum follow-up of 6 months. Three studies conducted by Hendriks et al., Stewart et al. and Carter et al. were included. The outcomes assessed were allcause mortality, cardiovascular and AF-related hospitalizations and cerebrovascular events. The results of the meta-analysis showed that there was $49 \%$ and $42 \%$ decrease in all-cause mortality and cardiovascular hospitalizations, respectively with integrated care. However, the integrated care had no effect on AF-related hospitalizations and cerebrovascular episodes. Further analysis revealed that 19 patients need to be treated by the integrated approach to prevent one death. With aspect to hospitalizations, the treatment of 18 patients will decrease one hospital admission [20].

In a randomized controlled trial conducted in the Netherlands, 712 patients with atrial fibrillation were randomly allocated to the usual care and nurse-led care group. Each group had 356 patients. The follow-up period was a minimum 1 year. The patients with AF of age $\geq 18$ years were eligible. Cardiovascular hospitalizations occurred in $48(13.5 \%)$ and $68(19.1 \%)$ patients in the nurse-led and usual care group, respectively. The death occurred in $4(1.1 \%)$ patients receiving integrated care in contrast to $14(3.9 \%)$ patients receiving usual care. In the usual care group, 3 patients died from a stroke whereas none of the patients died from stroke in the nurseled group [12].

A multicenter randomized controlled trial was conducted in Australia in which 335 patients were enrolled. The minimum follow-up period was 24 months with 168 patients in the SAFETY intervention group and 167 in the standard management group. 264(79\%) participants had an unplanned admission or death, out of which 127 were in the SAFETY group and 137 in the standard group. $19(11 \%)$ patients died in the SAFETY group and $30(18 \%)$ in the standard group. The median event-free survival was greater in the SAFETY group as compared to the standard group. The length of hospital stay in each admission was less in the SAFETY participants (2.8 days) in contrast to standard management patients (3.6 days). There was no statistical difference for readmissions for atrial fibrillation (54[32\%] in SAFETY group versus 57[34\%] in standard group). The cerebrovascular events were reported in $8(5 \%)$ patients in the SAFETY group and $6(4 \%)$ patients in the standard group [22].

A before-and-after study done in Nova Scotia included 413 patients with atrial fibrillation with age $\geq 18$ years. They included 185 patients in the AF clinic group and 228 patients were enrolled in the usual care group. The follow-up time was 21.5 months in the AF clinic and 28 months in the usual care group. Death was reported in $4(1.8 \%)$ patients in the usual care group whereas no patient died in the AF clinic group. $20(8.8 \%)$ patients had a hospital admission for a cardiovascular cause in the usual care group and $11(5.9 \%)$ in the AF clinic group. 25(13.5\%) and 54(23.7\%) patients had AF-related emergency (ED) visits in the AF clinic group and usual care group, respectively. Lower rates of stroke and bleeding were seen in both groups and the difference was not statistically significant. Stroke occurred in $4(2.2 \%)$ patients in the AF clinic group and $8(3.5 \%)$ patients in the usual care group. A greater percentage of patients were prescribed oral anticoagulants in the AF clinic group (57.7\%) as compared to the usual care group(39.3\%) [16].

In a randomized controlled study by Fuenzalida et al., 240 atrial fibrillation patients with age $\geq 18$ years were recruited. One hundred sixteen patients were included in the intervention group and 124 were enrolled in the control group. The follow-up period was 1 year. The death occurred in 18(10.43\%) and 26(20.96\%) patients in the intervention and control group, respectively. A total of 116 patients had ED visits with $51(43.96 \%)$ patients in the intervention group and 65(51.61\%) patients in the control group. Seventy four patients had hospital admissions with 31(26.72\%) in the intervention group and $43(34.67 \%)$ in the control group. The most common complication was heart failure occurring in $19(16.37 \%)$ and $33(26.61 \%)$ patients in the intervention and control group, respectively. The difference in other complications between the two groups was not significant [23].

A cluster-randomized, controlled trial was conducted by Vinereanu et al. in which 48 clusters were enrolled from 5 countries. The follow-up period was 12 months. The patients with atrial fibrillation who were $\geq 18$ years and had an indication of oral anticoagulation were included. The intervention and control group included 1184 and 1092 patients, respectively. In the intervention group, oral anticoagulant use increased from 804(68\%) patients at baseline to $943(80 \%)$ patients whereas, in the control group, the oral anticoagulant use increased from $703(64 \%)$ patients to $732(67 \%)$ patients after 1 year. The death occurred in $5 \%$ of the patients in both the intervention and control group. There was a marked decrease in stroke in the intervention group (11\%) in contrast to the control group (21\%). There was no difference in other secondary outcomes between the two groups [24].

In another randomized study, 31 patients were randomly allocated to the intervention group and 34 patients in the usual care group. The follow-up period was 5 years. The patients in the intervention group had a longer event-free survival of 34 months as compared to 17 months in the control group. The patients in the intervention group had fewer hospital readmissions $(1.9 \%)$ as compared to $2.5 \%$ in the usual care group. Similarly, the associated 
hospital stay was $16.3 \%$ in the intervention group in contrast to $20.3 \%$ in the usual care group [25].

In the ATHERO-AF cohort study, Pastoriet al. evaluated the risk reduction in cardiovascular events by implementing the Atrial fibrillation Better Care (ABC) pathway. The ABC pathway is an integrated care management program and includes prevention of stroke with anticoagulation, better management of symptoms and cardiovascular risk management. The study recruited 907consecutive patients with AF using vitamin $\mathrm{K}$ antagonists. The follow-up duration was 36.9 months. The patients managed using the ABC pathway had a lower risk of cardiovascular events [28]. Pastoriet al. also estimated the effect of $\mathrm{ABC}$ pathway on healthcare costs showing significantly lower health-related costs [29]. A posthoc analysis of the atrial fibrillation follow-up investigation of rhythm management (AFFIRM) trial was done between the ABC and non-ABC group of patients. The analysis showed that the patients managed with the ABC pathway had a lower risk of all-cause mortality, cardiovascular mortality, major bleeding, stroke and first hospitalization [30]. Yoon et al. included 204,842 nonvalvular AF patients in Korea with a follow-up duration of $6.2 \pm 3.5$ years. The patients were allocated into the $A B C$ and non- $A B C$ groups. The results reported lower rates of all-cause mortality, cardiovascular mortality, stroke, major bleeding, myocardial infarction and major bleeding in the $\mathrm{ABC}$ group in contrast to the non-ABC group [31]. The IMPACT-AF study was a randomized cluster trial conducted in
Canada to assess the improvement in care and outcomes in atrial fibrillation patients using the electronic Clinical Decision Support System (CDSS). It showed that that the integrated management program run by CDSS can be more cost-efficient as compared to usual AF care [32].

\section{Conclusion}

In comparison to the usual care, a multidisciplinary integrated care approach (i.e. nurse-led care along with usual specialist care) in atrial fibrillation patients is associated with reduced MACE/ NACE (net adverse clinical events), cardiovascular and AF-related hospitalizations \& mortality and all-cause mortality.

\section{Strengths and limitations}

The outcomes of the meta-analysis reiterate the importance of integrated care as an exceedingly effectual system of patient management. Analyzing results in RCTs and comparing the control group to the usual care provides significant evidence on the efficacy of the integrated care approach.

In comparison to the usual care, a multidisciplinary integrated care approach (i.e. nurse-led care along with usual specialist care) in atrial fibrillation patients is associated with reduced MACE/ NACE (net adverse clinical events), cardiovascular and AF-related hospitalizations \& mortality and all-cause mortality.

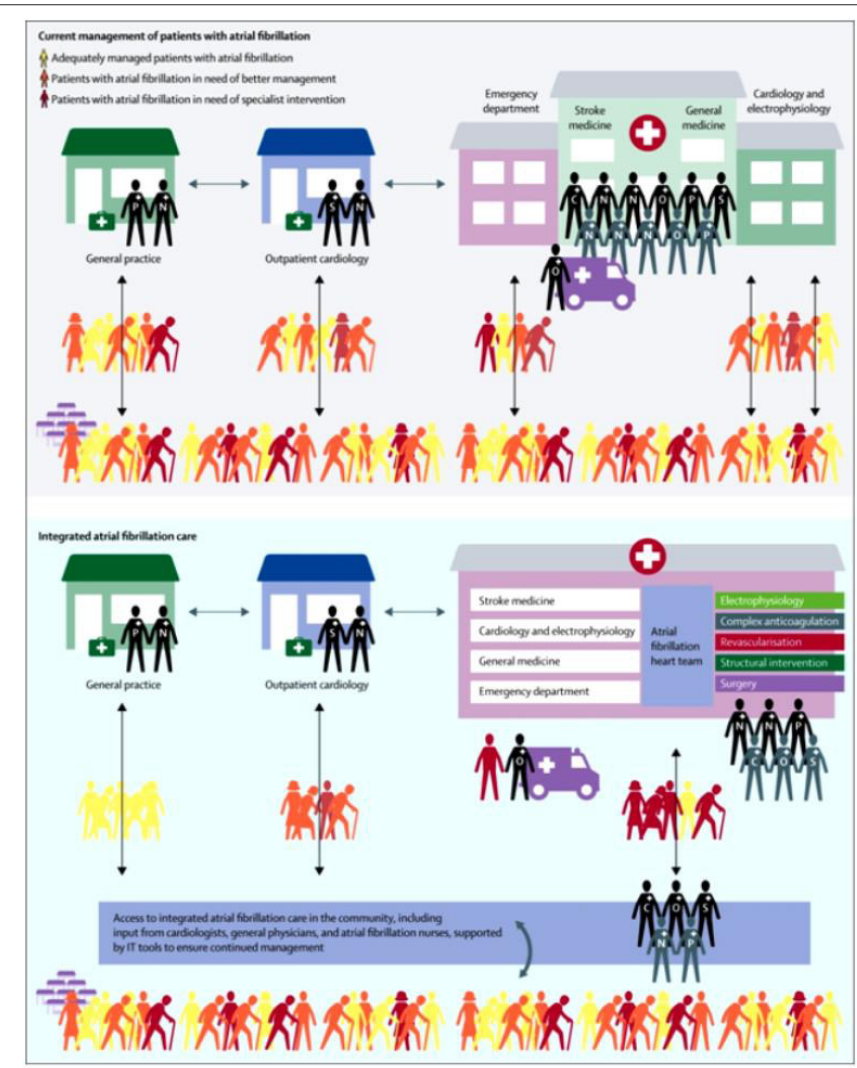

Figure 15: "Comparison between the structure of integrated atrial fibrillation care and current atrial fibrillation care" [34]. 
The study does have limitations.

1. It's not clear which component of integrated care is really responsible to make the difference.

2. Atrial fibrillation patients have co-morbidities and its uncertain as well as difficult to establish one system of integrated care.

This emphasizes the significance of the multidisciplinary integrated care approach having AF patient central to the concept and sustenance systems to assist provision of optimum practice and primarily recommendations and guideline supported care.

There's a need to further define the integrated care approaches and refine it in the best interest of patient. It should further stress and strongly advocate as a part of guidelines in AF care. The following (Figure 15) as elaborated by Kirchhof differentiates the current and proposed multidisciplinary integrated care approach for atrial fibrillation management [1].

\section{Funding sources}

This research did not receive any specific grant from funding agencies in the public, commercial, or not-for-profit sectors.

\section{Conflict of Interest}

None

\section{References}

1. Kirchhof P, Breithardt G, Bax J, Benninger G, Blomstrom-Lundqvist C, et al. (2016) A roadmap to improve the quality of atrial fibrillation management: proceedings from the fifth atrial fibrillation network/ European heart rhythm association consensus conference. Europace 18(1): $37-50$.

2. Lloyd-Jones DM, Wang TJ, Leip EP, Larson MG, Levy D, et al. (2004) Lifetime risk for development of atrial fibrillation: the Framingham heart study. Circulation 110(9): 1042-1046.

3. Wattigney WA, Mensah GA, Croft JB (2003) Increasing trends in hospitalization for atrial fibrillation in the United States, 1985 through 1999 implications for primary prevention. Circulation 108(6): 711-716.

4. Patel NJ, Deshmukh A, Pant S, Singh V, Patel N, et al. (2014) Contemporary trends of hospitalization for atrial fibrillation in the United States, 2000 through 2010 implications for healthcare planning. Circulation 129(23): 2371-2379.

5. Berti D, Hendriks JML, Brandes A, Deaton C, Crijns HJ, et al. (2013) A proposal for interdisciplinary, nurse-coordinated atrial fibrillation expert programmes as a way to structure daily practice. Eur Heart J 34(35): 2725-2730.

6. Wagner EH, Austin BT, Von Korff M (1996) Organizing care for patients with chronic illness. The Milbank Quarterly 74(4): 511-544.

7. Krumholz HM, Currie PM, Riegel B, Phillips CO, Peterson ED, et al. (2006) Taxonomy for disease management: a scientific statement from the American Heart Association Disease Management Taxonomy Writing Group. Circulation 114(13): 1432-1445.

8. Vale MJ, Jelinek MV, Best JD, Dart AM, Grigg LE, et al. (2003) Coaching patients on achieving cardiovascular health $(\mathrm{COACH})$ : a multicenter randomized trial in patients with coronary heart disease. Arch Intern Med 163(22): 2775-2783.

9. Takeda A,Taylor SJ,Taylor RS, Khan F, Krum H, Underwood M (2012) Clinical service organization for heart failure. Cochrane Database Syst Rev (9): CD002752.

10. McAlister FA, Lawson FM, Teo KK, Armstrong PW (2001) Randomized trials of secondary prevention programmes in coronary heart disease: systematic review. BMJ 323(7319): 957-962.

11. Nieuwlaat R, Eurlings LW, Cleland JG, Cobbe SM, Vardas PE, et al. (2009) Atrial fibrillation and heart failure in Cardiology practice: reciprocal impact and combined management from the perspective of atrial fibrillation. Results of the Euro Heart Survey on Atrial Fibrillation. J Am Coll Cardiol 53(18):1690-1698.

12. Hendriks JM, de Wit R, Crijns HJ, Vrijhoef HJ, Prins MH, et al. (2012) Nurse-led care vs. usual care for patients with atrial fibrillation: results of a randomized trial of integrated chronic care vs. routine clinical care in ambulatory patients with atrial fibrillation. Eur Heart J 33(21): 2692 2699.

13. Rienstra M, Lubitz SA, Mahida S, Magnani JW, Fontes JD, et al. (2012) Symptoms and functional status of patients with atrial fibrillation: State of the art and future research opportunities. Circulation 125(23): 29332943.

14. Kul S, Barbieri A, Milan E (2012) Effects of care pathways on the in-hospital treatment of heart failure: a systematic review. BMC Cardiovascular Disorders 12: 81.

15. Kotecha D, Breithard G, Camm AJ, Lip GY, Schotten U, et al. (2018) Integrating new approaches to atrial fibrillation management: the $6^{\text {th }}$ AFNET/EHRA Consensus Conference. Europace 20(3): 395-407.

16. Carter L, Gardner M, Magee K, Fearon A, Morgulis I, et al. (2016) An integrated management approach to atrial fibrillation. J Am Heart Assoc 5(1): e002950.

17. Leape L, Berwick D, Clancy C, Conway J, Gluck P, et al. (2009) Transforming healthcare: a safety imperative. Qual Saf Health Care 18(6): 424-428.

18. Martinez-Gonzalez NA, Berchtold P, Ullman K, Busato A, Egger M (2014) Integrated care programmes for adults with chronic conditions: a metareview. Int J Qual Health Care 26(5): 561-570.

19. Shaw S, Rosen R, Rumbold B (2011) What is integrated care? Research report.

20. Gallagher C, Elliott AD, Wong CX, Rangnekar G, Middeldorp ME, et al. (2017) Integrated care in atrial fibrillation: a systematic review and meta-analysis. Heart 103(24): 1947-1953.

21. Hendriks JM, Vrijhoef HJ, Crijns HJ, Brunner-La Rocca HP (2014) The effect of a nurse-led integrated chronic care approach on quality of life in patients with atrial fibrillation. Europace 16(4): 491-499.

22. Stewart S, Ball J, Horowitz JD, Marwick TH, Mahadevan G, et al. (2015) Standard versus atrial fibrillation-specific management strategy (SAFETY) to reduce recurrent admission and prolong survival: pragmatic, multicentre randomized controlled trial. Lancet 385(9970): 775-784.

23. Fuenzalida C, Hernandez G, Ferro I, Siches C, Ambros A (2017) Longterm benefits of education by emergency care nurses at discharge of patients with atrial fibrillation. Int Emerg Nurs 35: 7-12.

24. Vinereanu D (2017) A multifaceted intervention to improve treatment with oral anticoagulants in atrial fibrillation (IMPACT-AF): a n international, cluster-randomized trial. Lancet 390(10104): 1737-1747.

25. Inglis S, McLennan S, Dawson A, Birchmore L, Horowitz JD, et al. (2004) A new solution for an old problem? Effects of a nurse-led, multidisciplinary, home-based intervention on readmission and mortality in patients with chronic atrial fibrillation. J CardiovascNurs 19(2): 118-127. 
26. Bowyer JL, Tully PJ, Ganesan AN, Chahadi FK, Singleton CB, et al. (2017) A randomized controlled trial on the effect of nurse-led educational intervention at the time of catheter ablation for atrial fibrillation on quality of Life, symptom severity and rehospitalization. Heart, Lung and Circulation 26(1): 73-81.

27. Hendriks J, Tomini F, van Asselt T, Crijns H, Vrijhoef H (2013) Costeffectiveness of a specialized atrial fibrillation clinic vs. usual care in patients with atrial fibrillation. Europace 15(8): 1128-1135.

28. Pastori D, Pignatelli P, Menichelli D, Violi F, Lip GYH (2019) Integrated care management of patients with atrial fibrillation and risk of cardiovascular events: the ABC (Atrial fibrillation Better Care) pathway in the ATHERO-AF study cohort. Mayo Clin Proc 94(7): 1261-1267.

29. PastoriD, Farcomeni A, PignatelliP, VioliF, Lip GY (2019) ABC (Atrial fibrillation Better Care) pathway and healthcare costs in atrial fibrillation: the ATHERO-AF study. Am J Med 132(7): 856-861.

30. Proietti M, Romiti GF, Olshansky B, Lane DA, Lip GY (2018) Improved outcomes by integrated care of anticoagulated patients with atrial fibrillation using the simple $\mathrm{ABC}$ (Atrial Fibrillation Better Care) pathway. Am J Med 131(11): 1359-1366.

31. Yoon M, Yang PS, Jang E, Yu HT, Kim TH, et al. (2019) Improved population-based clinical outcomes of patients with atrial fibrillation by compliance with the simple ABC (Atrial Fibrillation Better Care) pathway for integrated care management: a nationwide cohort study. ThrombHaemost 19(10):1695-1703.

32. Cox JL, Parkash R, Abidi SS, Thabane L, Xie F, et al. (2018) Optimizing primary care management of atrial fibrillation: the rationale and methods of the Integrated Management Program Advancing Community Treatment of Atrial Fibrillation (IMPACT-AF) study. Am Heart J 201: 149157.

33. Lau DH, Schotten U, Mahajan R, Antic NA, Hatem SN, et al. (2016) Novel mechanisms in the pathogenesis of atrial fibrillation: practical applications. EurHeart J 37(20): 1573-1581.

34. Kirchhof P (2017) The future of atrial fibrillation management: integrated care and stratified therapy. Lancet 390(10105): 1873-1887.

\section{Appendix}

Appendix A

\begin{tabular}{|c|c|c|}
\hline "atrial fibrillation" & $\begin{array}{l}\text { Delivery of Health Care, } \\
\text { Integrated [mhipeexp] OR } \\
\text { "integrated health care" OR } \\
\text { "integrated healthcare" OR } \\
\text { "integrated care" OR } \\
\text { multidisciplinary OR } \\
\text { "ambulatory care" OR } \\
\text { Outpatient" }\end{array}$ & 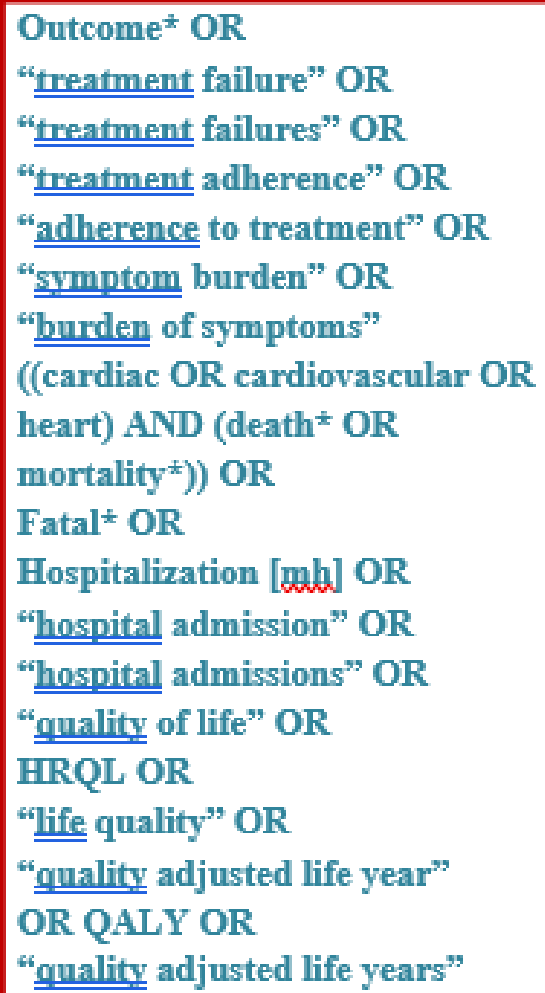 \\
\hline
\end{tabular}




\section{Appendix B}

\section{MEDLINE (PUBMED)}

(("atrial fibrillation" AND Randomized Controlled Trial[ptyp] AND Humans[Mesh] AND English[lang])) AND (()((Delivery of Health Care, Integrated [mh:noexp] OR "integrated health care" OR "integrated healthcare" OR "integrated care" OR multidisciplinary OR "ambulatory care" OR Outpatient*)) AND Randomized Controlled Trial[ptyp] AND Humans[Mesh] AND English[lang])) OR (((Outcome* OR "treatment failure" OR "treatment failures" OR "treatment adher ence" OR "adherence to treatment" OR "symptom burden" OR "burden of symptoms" ((cardiac OR cardiovascular OR heart) AND (death* OR mortality*)) OR Fatal* OR Hospitalization [mh] OR "hospital admission" OR "hospital admissions" OR "quality of life" OR HRQL OR "life quality" OR "quality adjusted life year" OR OALY OR "quality adjusted life years")) AND Randomized Controlled Trial[ptyp] AND Humans[Mesh] AND English(lang])) AND Randomized Controlled Trial [ptyp] AND Humans[Mesh] AND English[lang]) Filters: Randomized Controlled Trial; Humans; English

(("atrial fibrillation"[MeSH Terms] OR ("atrial"[All Fields] AND "fibrillation"[All Fields]) OR "atrial fibrillation"[All Fields]) AND ("Int J Integr Care"[Journal] OR ("integrated"[All Fields] AND "care"[All Fields]) OR "integrated care"[All Fields])) OR (""atrial fibrillation"[MeSH Terms] OR ("atrial"[All Fields] AND "fibrillation"[All Fields]) OR "atrial fibrillation"[All Fields]) AND (("interdisciplinary studies"[MeSH Terms] OR ("interdisciplinary"[All Fields] AND "studies"[All Fields]) OR "interdisciplinary studies"[All Fields] OR "multidisciplinary"[All Fields]) AND care[All Fields])) AND Clinical Trial[ptyp] Filters: Randomized Controlled Trial; English

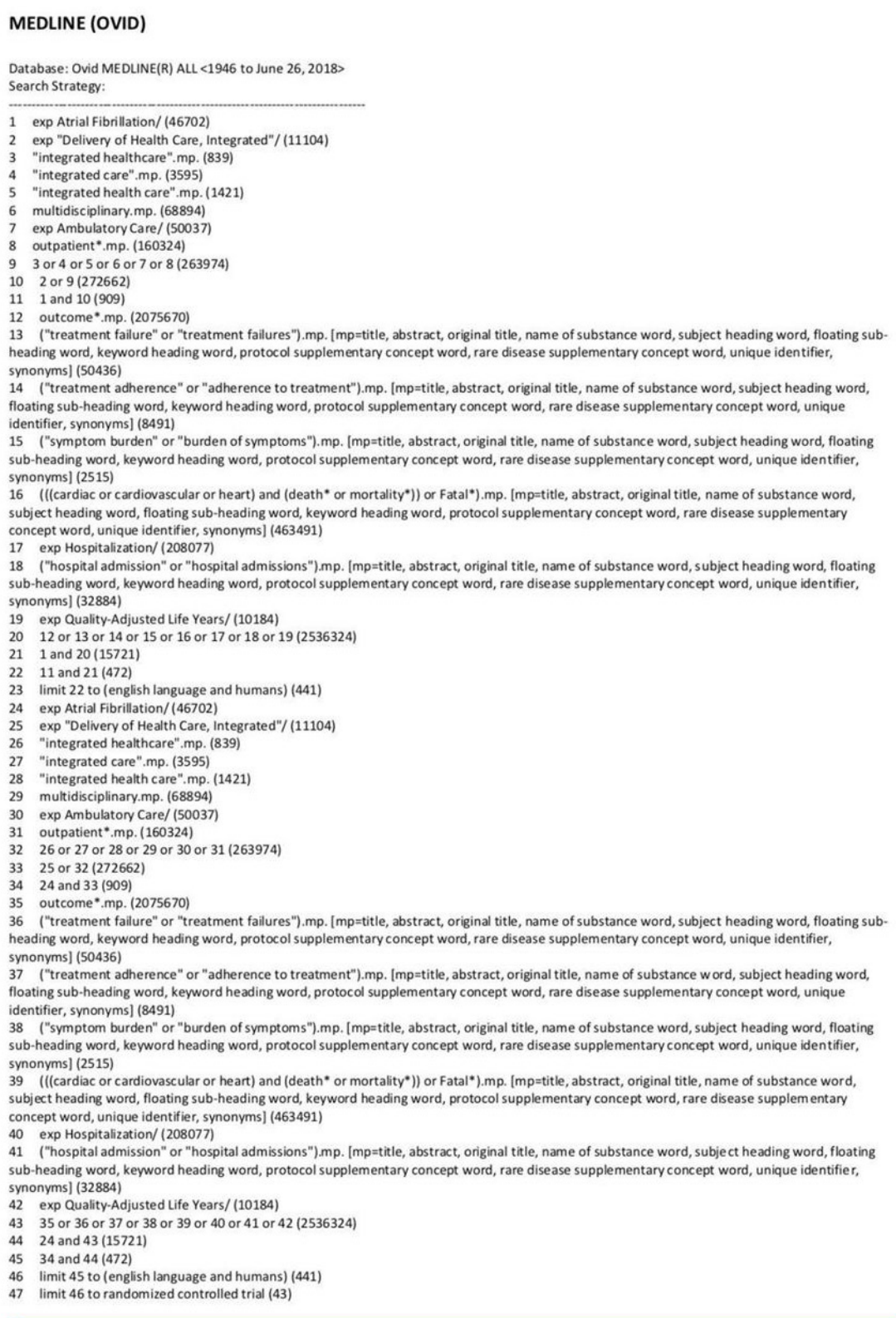




\section{EMBASE (OVID)}

Database: Embase <1974 to 2018 June 27>

Search Strategy:

1 exp Atrial Fibrillation/ (42539)

exp "Delivery of Health Care, Integrated"/ (9792)

"integrated healthcare".mp. (1348)

"integrated care".mp. (4718)

"integrated health care".mp. (10827)

multidisciplinary.mp. (109195)

7 exp Ambulatory Care / (46533)

outpatient*.mp. (282859)

93 or 4 or 5 or 6 or 7 or $8(436974)$

102 or $9(436974)$

111 and $10(1760)$

12 outcome*.mp. (2784169)

13 ("treatment failure" or "treatment failures").mp. [mp=title, abstract, heading word, drug trade name, original title, device manufacturer, drug manufacturer, device trade name, keyword, floating subheading word, candidate term word] (139937)

14 ("treatment adherence" or "adherence to treatment").mp. [mp=title, abstract, heading word, drug trade name, original title, device manufacturer, drug manufacturer, device trade name, keyword, floating subheading word, candidate term word] (14168)

15 ("symptom burden" or "burden of symptoms").mp. [mp=title, abstract, heading word, drug trade name, original title, device manufacturer, drug manufacturer, device trade name, keyword, floating subheading word, candidate term word] (4857)

16 ( ((cardiac or cardiovascular or heart) and (death* or mortality*)) or Fatal*).mp. [mp=title, abstract, heading word, drug trade name, original title, device manufacturer, drug manufacturer, device trade name, keyword, floating subheading word, candidate term word] (784246)

17 exp Hospitalization/ (310717)

18 ("hospital admission" or "hospital admissions").mp. [mp=title, abstract, heading word, drug trade name, original title, device manufacturer, drug manufacturer, device trade name, keyword, floating subhead ing word, candidate term word] (182693)

19 exp Quality-Adjusted Life Years/ (21341)

2012 or 13 or 14 or 15 or 16 or 17 or 18 or $19(3705419)$

211 and $20(20245$

2211 and 21 (985)

23 limit 22 to (english language and humans) (965)

$24 \exp$ Atrial Fibrillation/ (42539)

25 exp "Delivery of Health Care, Integrated"/ (9792)

26 "integrated healthcare".mp. (1348)

27 "integrated care".mp. (4718)

28 "integrated health care".mp. (10827)

29 multidisciplinary.mp. (109195)

30 exp Ambulatory Care/ (46533)

31 outpatient*.mp. (282859)

3226 or 27 or 28 or 29 or 30 or 31 (436974)

3325 or $32(436974)$

3424 and $33(1760)$

35 outcome*.mp. (2784169)

36 ("treatment failure" or "treatment failures").mp. [mp=title, abstract, heading word, drug trade name, original title, device manufacturer, drug manufacturer, device trade name, keyword, floating subheading word, candidate term word] (139937)

37 ("treatment adherence" or "adherence to treatment").mp. [mp=title, abstract, heading word, drug trade name, original title, device manufacturer, drug manufacturer, device trade name, keyword, floating subheading word, candidate term word] (14168)

38 ("symptom burden" or "burden of symptoms").mp. [mp=title, abstract, heading word, drug trade name, original title, device manufacturer, drug manufacturer, device trade name, keyword, floating subheading word, candidate term word] (4857)

39 (( (cardiac or cardiovascular or heart) and (death* or mortality*)) or Fatal*).mp. [mp=title, abstract, heading word, drug trade name, original

title, device manufacturer, drug manufacturer, device trade name, keyword, floating subheading word, candidate term word] (784246)

40 exp Hospitalization/ (310717)

41 ("hospital admission" or "hospital admissions").mp. [mp=title, abstract, heading word, drug trade name, original title, device manufacturer, drug manufacturer, device trade name, keyword, floating subheading word, candidate term word] (182693)

42 exp Quality-Adjusted Life Years/ (21341)

4335 or 36 or 37 or 38 or 39 or 40 or 41 or $42(3705419)$

4424 and $43(20245)$

4534 and $44(985)$

46 limit 45 to (english language and humans) (965)

47 limit 46 to randomized controlled trial (33) 


\section{Appendix C}

\begin{tabular}{|c|c|c|c|}
\hline Section/topic & $\#$ & Checklist item & $\begin{array}{l}\text { Reported } \\
\text { on page \# }\end{array}$ \\
\hline \multicolumn{4}{|l|}{ TITLE } \\
\hline Title & 1 & Identify the report as a systematic review, meta-analysis, or both. & 1 \\
\hline \multicolumn{4}{|l|}{ ABSTRACT } \\
\hline $\begin{array}{l}\text { Structured } \\
\text { summary }\end{array}$ & 2 & $\begin{array}{l}\text { Provide a structured summary including, as applicable: background; objectives; data sources; study } \\
\text { eligibility criteria, participants, and interventions; study appraisal and synthesis methods; results; } \\
\text { limitations; conclusions and implications of key findings; systematic review registration number. }\end{array}$ & 2 \\
\hline \multicolumn{4}{|l|}{ INTRODUCTION } \\
\hline Rationale & 3 & Describe the rationale for the review in the context of what is already known. & 4 \\
\hline Objectives & 4 & $\begin{array}{l}\text { Provide an explicit statement of questions being addressed with reference to participants, interventions, } \\
\text { comparisons, outcomes, and study design (PICOS). }\end{array}$ & 4 \\
\hline \multicolumn{4}{|l|}{ METHODS } \\
\hline $\begin{array}{l}\text { Protocol and } \\
\text { registration }\end{array}$ & 5 & $\begin{array}{l}\text { Indicate if a review protocol exists, if and where it can be accessed (e.g., Web address), and, if available, } \\
\text { provide registration information including registration number. }\end{array}$ & 5 \\
\hline Eligibility criteria & 6 & $\begin{array}{l}\text { Specify study characteristics (e.g., PICOS, length of follow-up) and report characteristics (e.g., years } \\
\text { considered, language, publication status) used as criteria for eligibility, giving rationale. }\end{array}$ & 6 \\
\hline $\begin{array}{l}\text { Information } \\
\text { sources }\end{array}$ & 7 & $\begin{array}{l}\text { Describe all information sources (e.g., databases with dates of coverage, contact with study authors to } \\
\text { identify additional studies) in the search and date last searched. }\end{array}$ & 8 \\
\hline Search & 8 & $\begin{array}{l}\text { Present full electronic search strategy for at least one database, including any limits used, such that it } \\
\text { could be repeated. }\end{array}$ & 31 \\
\hline Study selection & 9 & $\begin{array}{l}\text { State the process for selecting studies (i.e., screening, eligibility, included in systematic review, and, if } \\
\text { applicable, included in the meta-analysis). }\end{array}$ & 10 \\
\hline $\begin{array}{l}\text { Data collection } \\
\text { process }\end{array}$ & 10 & $\begin{array}{l}\text { Describe method of data extraction from reports (e.g., piloted forms, independently, in duplicate) and } \\
\text { any processes for obtaining and confirming data from investigators. }\end{array}$ & 8 \\
\hline Data items & 11 & $\begin{array}{l}\text { List and define all variables for which data were sought (e.g., PICOS, funding sources) and any } \\
\text { assumptions and simplifications made. }\end{array}$ & 8 \\
\hline $\begin{array}{l}\text { Risk of bias in } \\
\text { individual studies }\end{array}$ & 12 & $\begin{array}{l}\text { Describe methods used for assessing risk of bias of individual studies (including specification of } \\
\text { whether this was done at the study or outcome level), and how this information is to be used in any data } \\
\text { synthesis. }\end{array}$ & $10 / 11$ \\
\hline $\begin{array}{l}\text { Summary } \\
\text { measures }\end{array}$ & 13 & State the principal summary measures (e.g., risk ratio, difference in means). & 8 \\
\hline $\begin{array}{l}\text { Synthesis of } \\
\text { results }\end{array}$ & 14 & $\begin{array}{l}\text { Describe the methods of handling data and combining results of studies, if done, including measures of } \\
\text { consistency (e.g., I2) for each meta-analysis }\end{array}$ & 8 \\
\hline Section/topic & $\#$ & Checklist item & $\begin{array}{l}\text { Reported } \\
\text { on page \# }\end{array}$ \\
\hline $\begin{array}{l}\text { Risk of bias across } \\
\text { studies }\end{array}$ & 15 & $\begin{array}{l}\text { Specify any assessment of risk of bias that may affect the cumulative evidence } \\
\text { (e.g., publication bias, selective reporting within studies). }\end{array}$ & $10 / 11$ \\
\hline $\begin{array}{l}\text { Additional } \\
\text { analyses }\end{array}$ & 16 & $\begin{array}{l}\text { Describe methods of additional analyses (e.g., sensitivity or subgroup analyses, } \\
\text { meta-regression), if done, indicating which were pre-specified. }\end{array}$ & - \\
\hline \multicolumn{4}{|l|}{ RESULTS } \\
\hline Study selection & 17 & $\begin{array}{l}\text { Give numbers of studies screened, assessed for eligibility, and included in the review, with reasons for } \\
\text { exclusions at each stage, ideally with a flow diagram. }\end{array}$ & 12 \\
\hline $\begin{array}{c}\text { Study } \\
\text { characteristics }\end{array}$ & 18 & $\begin{array}{l}\text { For each study, present characteristics for which data were extracted (e.g., study size, PICOS, follow-up } \\
\text { period) and provide the citations. }\end{array}$ & 12 \\
\hline $\begin{array}{l}\text { Risk of bias } \\
\text { within } \\
\text { studies }\end{array}$ & 19 & Present data on risk of bias of each study and, if available, any outcome level assessment (see item 12). & $10 / 11$ \\
\hline $\begin{array}{l}\text { Results of } \\
\text { individual } \\
\text { studies }\end{array}$ & 20 & $\begin{array}{l}\text { For all outcomes considered (benefits or harms), present, for each study: (a) simple summary data for } \\
\text { each intervention group (b) effect estimates and confidence intervals, ideally with a forest plot. }\end{array}$ & $16-21$ \\
\hline
\end{tabular}




\begin{tabular}{|c|c|c|c|}
\hline $\begin{array}{l}\text { Synthesis of } \\
\text { results }\end{array}$ & 21 & Present results of each meta-analysis done, including confidence intervals and measures of consistency. & $16-21$ \\
\hline $\begin{array}{l}\text { Risk of bias across } \\
\text { studies }\end{array}$ & 22 & Present results of any assessment of risk of bias across studies (see Item 15). & $10 / 11$ \\
\hline $\begin{array}{l}\text { Additional } \\
\text { analysis }\end{array}$ & 23 & $\begin{array}{l}\text { Give results of additional analyses, if done (e.g., sensitivity or subgroup analyses, meta-regression [see } \\
\text { Item 16]). }\end{array}$ & - \\
\hline \multicolumn{4}{|l|}{ DISCUSSION } \\
\hline $\begin{array}{l}\text { Summary of } \\
\text { evidence }\end{array}$ & 24 & $\begin{array}{l}\text { Summarize the main findings including the strength of evidence for each main outcome; consider their } \\
\text { relevance to key groups (e.g., healthcare providers, users, and policy makers). }\end{array}$ & 21 \\
\hline Limitations & 25 & $\begin{array}{l}\text { Discuss limitations at study and outcome level (e.g., risk of bias), and at review- level (e.g., incomplete } \\
\text { retrieval of identified research, reporting bias). }\end{array}$ & 25 \\
\hline Conclusions & 26 & $\begin{array}{c}\text { Provide a general interpretation of the results in the context of other evidence, and implications for } \\
\text { future research. }\end{array}$ & 25 \\
\hline \multicolumn{4}{|l|}{ FUNDING } \\
\hline Funding & 27 & $\begin{array}{l}\text { Describe sources of funding for the systematic review and other support (e.g., supply of data); role of } \\
\text { funders for the systematic review. }\end{array}$ & 1 \\
\hline
\end{tabular}

\section{PRISMA Checklist}

